Eleventh Floor

Menzies Building

PO Box 11E, Monash University

Wellington Road

CLAYTON VIC 3800 AUSTRALIA

Telephone:

(03) 9905 2398, (03) 99055112

Fax:

(03) 99052426

e-mail

web site from overseas:

61399055112 or 61399052398

61399052426

impact@buseco.monash.edu.au

http://www.monash.edu.au/policy/

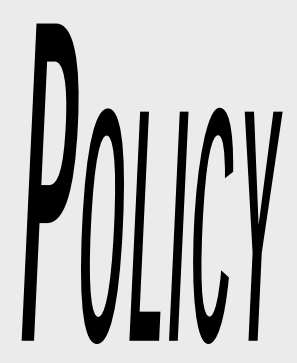

THE US ECONOMY FROM 1992 TO 1998: HISTORICAL AND DECOMPOSITION SIMULATIONS WITH THE USAGE MODEL

by

Peter B. DIXON

and

Maureen T. RIMMER

Centre of Policy Studies, Monash University

General Working Paper No. G-143 October 2003

ISSN 10319034

ISBN 0732615488

The Centre of Policy Studies (COPS) is a research centre at Monash University devoted to quantitative analysis of issues relevant to Australian economic policy. 



\begin{abstract}
USAGE is a 500 industry dynamic computable general equilibrium model of the US economy being developed at Monash University in collaboration with the US International Trade Commission. In common with the MONASH model of Australia, USAGE is designed for four modes of analysis:

Historical, where we estimate changes in technology and consumer preferences;

Decomposition, where we explain periods of economic history in terms of driving factors such as changes in technology and consumer preferences;

Forecast, where we derive basecase forecasts for industries, occupations and regions that are consistent with trends from historical simulations and with available expert opinions; and

Policy, where we derive deviations from basecase forecast paths caused by assumed policies.

This paper reports our first set of historical and decomposition results. The historical results quantify several aspects of technical change in US industries for the period 1992 to 1998 including: intermediate-input-saving technical change; primary-factor-saving technical change; labor-capital bias in technical change; and import-domestic bias in technical change. The historical results also quantify shifts in consumer preferences between commodities. The decomposition results are applied in illustrative analyses of growth in US international trade between 1992 and 1998 and of growth in the US steel industry for this period.

JEL Classification: C68, D58, F14.
\end{abstract}




\section{Contents}

1. Introduction 1

2. USAGE-ITC, background information 1

3. Historical and decomposition closures 3

4. Historical simulation for 1992 to $1998 \quad 7$

5. Decomposition simulation for 1992 to 1998

5.1 Macroeconomic assumptions in the decomposition simulation 21

5.2 Decomposition simulation: macro results 25

5.3 Cross-column analysis: growth in US trade between 1992 and 1998

5.4 Decomposition simulation: results for Iron \& Steel (IS) and Iron \& Steel Forging (ISF) 34

6. Concluding remarks 36

$\begin{array}{ll}\text { References } & 45\end{array}$

\section{Tables and Figures}

Table 4.1. Categories of Variables in the Historical and Decomposition Closures

Table 4.2. Abridged results from the historical simulation for 1992 to 1998 and selected data for 1992

Table 5.1. Macroeconomic variables: Decomposition of changes from 1992 to 1998

Table 5.1A. US trade: Decomposition of growth from 1992 to 1998

Table 5.2. $\quad$ Iron \&Steel (IS) and Iron \& Steel Forging (ISF):

Analysis of growth from 1992 to 1998

Figure 5.1. Macro connections in the decomposition simulation for 1992 to 1998 


\title{
The US economy from 1992 to 1998: historical and decomposition simulations with the USAGE model
}

by

\author{
Peter B. Dixon and Maureen T. Rimmer \\ Centre of Policy Studies \\ Monash University \\ October 3, 2003
}

\section{Introduction}

We apply the USAGE-ITC model to estimate changes in industry technologies and household preferences for the period 1992 to 1998 . We then use these estimates, together with information on a variety of other naturally exogenous variables, to explain changes between 1992 and 1998 in structural aspects of the United States economy including the industrial composition of output and the growth in US trade relative to GDP.

Section 2 contains brief background information on USAGE-ITC. Section 3 provides descriptions of the historical and decomposition closures. The historical closure is used in estimating changes in technologies and preferences and the decomposition closure is used in explaining structural developments. Section 4 contains details of our historical simulation for 1992 to 1998, including descriptions of the data input and results. Section 5 contains details of our decomposition simulation for 1992 to 1998, concentrating on the explanation of growth in trade. Section 5 also contains an illustrative industry analysis, for iron and steel. Concluding remarks are in section 6 .

\section{USAGE-ITC, background information}

USAGE-ITC is a detailed, dynamic, computable general equilibrium model of the US being developed by the Centre of Policy Studies (CoPS) at Monash University (Australia) in collaboration with the US International Trade Commission (ITC).

The model has 500 industries/commodities and allows for multiple trading partners. These features will be appealing to people concerned with environmental and trade issues. The industry detail will allow pollution coefficients to be sharply associated with the activities that produce the pollution and the trade-partner detail will facilitate analysis of trade agreements. Dynamic aspects of the model include specifications of capital flows into and out of the United States together with relationships between capital flows, the balance of payments, the public sector budget and US foreign assets and liabilities. 
USAGE-ITC shares many features with the MONASH model of Australia. Over the last twenty-five years, MONASH and its predecessor ORANI have been applied to a wide range of issues and are the basis for several hundred published papers. ${ }^{1}$ In common with MONASH, USAGE-ITC will have 4 classes of closures:

Historical, where we estimate changes in technology and consumer preferences;

Decomposition, where we explain periods of economic history in terms of driving factors such as changes in technology and consumer preferences;

Forecast, where we derive basecase forecasts for industries, occupations and regions that are consistent with trends from historical simulations and with available expert opinions; and

Policy, where we derive deviations from basecase forecast paths caused by assumed policies.

Also in common with MONASH, USAGE will have several add-on programs, that is programs that process results from the main model but do not affect those results. The first three of these add-ons for USAGE will allow results to be generated for the State economies, for disaggregated occupations and for different types of households (distributional issues). A subsequent add-on will allow USAGE to be applied in analyses of adjustment costs. As explained by Dixon and Rimmer (2002, pp 289-299) USAGE has the four ingredients required for such analyses: dynamics; detail; economy-wide focus; and forecasting capability.

For USAGE, we have completed: (a) the development of a database for 1992; (b) the development of historical shocks for 1992 to 1998; (c) an historical simulation for 1992 to 1998 that reveals for this period detailed estimates of changes in technology and consumer preferences; and (d) a decomposition simulation for 1992 to 1998 that explains the development of the US economy for this period in terms of exogenous driving factors including changes in technology and consumer preferences. From here it will be a relatively short step to forecast simulations (which rely heavily on results from historical simulations) and policy simulations (which require the basecase forecasts). The add-on programs will then be developed to extend the scope of the model in all four modes to cover States, occupations, income distribution and adjustment costs.

\footnotetext{
1 Comprehensive descriptions of ORANI and MONASH can be found in Dixon et al. (1982) and Dixon and Rimmer (2002). The ORANI/MONASH methodology has been adopted in many CGE modeling projects throughout the world. This has been facilitated by the GEMPACK software developed at CoPS by Ken Pearson [see for example Pearson (1988), Harrison and Pearson (1996) and Harrison et al. (1996)]. Outside Australia, the best-known application of ORANI/MONASH technology using GEMPACK programs is GTAP [see Hertel (1997)].
} 


\section{Historical and decomposition closures}

For each year, USAGE-ITC takes the form

$$
\mathrm{F}(\mathrm{X})=0
$$

where $\mathrm{F}$ is an $\mathrm{m}$-vector of differentiable functions of $\mathrm{n}$ variables $\mathrm{X}$, and $\mathrm{n}>\mathrm{m}$. The variables $\mathrm{X}$ include prices and quantities applying for a given year and the $m$ equations in (3.1) impose the usual CGE conditions such as: demands equal supplies; demands and supplies reflect utility and profit maximizing behaviour; prices equal unit costs; and end-of-year capital stocks equal depreciated opening capital stocks plus investment.

In using USAGE-ITC we always have available a solution $\left(\mathrm{X}_{\text {initial }}\right)$ of (3.1) derived mainly from input-output data for a particular year. In simulations, we compute the movements in $\mathrm{m}$ variables (the endogenous variables) away from their values in the initial solution caused by movements in the remaining $n-m$ variables (the exogenous variables) away from their values in the initial solution. In most simulations the movements in the exogenous variables are from their values in one year to their values in the next year. Correspondingly, the results for the endogenous variables refer to movements from one year to the next. However, in the historical and decomposition simulations considered in this paper, the initial solution is for 1992 and the movements in the exogenous variables refer to changes over the six years from 1992 to 1998. Thus, in these simulations, the movements in the endogenous variables refer to the six-year period from 1992 to 1998.

USAGE-ITC allows many closure choices, that is choices of the $n-m$ variables to be included in the exogenous set. In a decomposition closure we include in the exogenous set all naturally exogenous variables, i.e., variables not normally explained in a CGE model. These may be observable variables such as tax rates or unobservables such as technology and preference variables.

Historical closures include in their exogenous set two types of variables: observables and assignables. Observables are those for which movements can be readily observed from statistical sources for the period of interest. For example, in our 1992-1998 applications (sections 4 and 5), the observables include a wide array of macro and industry variables. The key feature of an assignable variable in an historical simulation is that its movement can be assigned a value (possibly not unique) without contradicting anything that we have observed about the historical period or wish to assume about that period. We clarify this concept later in this section in the discussion of (3.2).

With reference to the two closures we can partition USAGE-ITC variables into four parts:

$$
\mathrm{X}(\mathrm{HD}), \mathrm{X}(\mathrm{H} \overline{\mathrm{D}}), \mathrm{X}(\overline{\mathrm{H}} \mathrm{D}), \mathrm{X}(\overline{\mathrm{HD}})
$$


where

$\mathrm{H}$ denotes exogenous in the historical closure,

$\overline{\mathrm{H}}$ denotes not exogenous (that is endogenous) in the historical closure, and

$\mathrm{D}$ and $\overline{\mathrm{D}}$ denote exogenous and endogenous in the decomposition closure.

Among the variables in $\mathrm{X}(\mathrm{HD})$ are population size, foreign currency prices of imports and policy variables such as tax rates, tariff rates and public consumption. The values of these variables are readily observable (included in $\mathrm{H}$ ) and are not normally explained in CGE models (included in D).

Examples of variables in $\mathrm{X}(\overline{\mathrm{HD}})$ are demands for intermediate inputs and demands for margins services (e.g. road transport) to facilitate commodity flows from producers to users. In the absence of end-of-period input-output tables, movements in these variables are not readily observable or assignable (not included in $\mathrm{H}$ ) and are normally explained in CGE models (not included in D).

Variables in $\mathrm{X}(\mathrm{H} \overline{\mathrm{D}})$ include, at the industry or commodity level, outputs, employment, capital, investment, exports, imports, private consumption and numerous price deflators. Also included in $\mathrm{X}(\mathrm{H} \overline{\mathrm{D}})$ are numerous macro variables e.g., the exchange rate and the average wage rate. CGE models normally aim to explain the effects on these variables of policy changes, changes in technology and other changes in the economic environment. Hence these variables are naturally endogenous, i.e. they belong to the $\overline{\mathrm{D}}$ set, and because changes in their values can be readily observed they belong to the $\mathrm{H}$ set.

$\mathrm{X}(\overline{\mathrm{H}} \mathrm{D})$ contains the same number of variables as $\mathrm{X}(\mathrm{H} \overline{\mathrm{D}})$ with each variable in $\mathrm{X}(\mathrm{H} \overline{\mathrm{D}})$ having a corresponding variable in $\mathrm{X}(\overline{\mathrm{H}} \mathrm{D})$. These corresponding variables are predominantly unobservable technological and preference variables. Such variables are not normally explained by CGE models and are therefore exogenous in the decomposition closure. However in the historical closure they are endogenous with the role of giving USAGE-ITC enough flexibility to explain the observed movements in the variables in $\mathrm{X}(\mathrm{H} \overline{\mathrm{D}})$. Table 4.1, to be discussed in detail in section 4, shows examples of corresponding pairs from $X(\bar{H} D)$ and $X(H \bar{D})$. As indicated in the table, in our historical simulation we use shifts in household preferences to accommodate observations on consumption by commodity, twists in import-domestic preferences to accommodate observations on import volumes, etc.

The principles underlying the four-way partitioning of the USAGE-ITC variables in the historical and decomposition closures can be clarified by an example. A stylized version of the USAGE-ITC equation for total intermediate demand of commodity $\mathrm{i}\left(\mathrm{X}_{\mathrm{i}}\right)$ is

$$
X_{i}=\sum_{j} B_{i j} B_{i} Z_{j}
$$


where

$Z_{j}$ is the activity level (overall level of output) in industry $j$; and

$B_{i j} B_{i}$ is the input of $i$ per unit of activity in industry $j$ with $B_{i j}$ and $B_{i}$ being technological variables which can be used in simulating the effects of changes in the input of $i$ per unit of activity in $j$ and the input of i per unit of activity in all industries.

In decomposition mode, $B_{i j}$ and $B_{i}$ are exogenous and $Z_{j}$ and $X_{i}$ are endogenous. Suppose that movements in the $Z_{j}$ s are not observed but that we have observed the movements over an historical period in $\mathrm{X}_{\mathrm{i}}$ (possibly from information on commodity outputs, imports and final usage). Suppose that we wish to assume uniform input-i-using technical change. Then in historical mode we can use movements in $B_{i}$ to explain observed movements in $X_{i}$ and we can assign a uniform value (possibly zero) to the percentage movements in $B_{i j}$ for all $j$. In this example, $Z_{j}$ is a member of $X(\overline{H D})$ and the assignable variable $B_{i j}$ is a member of $X(H D) . X_{i}$ is a member of $X(H \bar{D})$ and $B_{i}$ is the corresponding member of $\mathrm{X}(\overline{\mathrm{H}} \mathrm{D})$.

Having allocated the USAGE-ITC variables to the four categories, we can compute historical and decomposition solutions, starting with the historical solution of the form:

$$
\mathrm{X}(\overline{\mathrm{H}})=\mathrm{G}^{\mathrm{H}}(\mathrm{X}(\mathrm{H}))
$$

where $\mathrm{X}(\mathrm{H})$ and $\mathrm{X}(\overline{\mathrm{H}})$ are the exogenous and endogenous variables in the historical closure, i.e. $\mathrm{X}(\mathrm{H})=\mathrm{X}(\mathrm{HD}) \cup \mathrm{X}(\mathrm{H} \overline{\mathrm{D}})$ and $\mathrm{X}(\overline{\mathrm{H}})=\mathrm{X}(\overline{\mathrm{H}} \mathrm{D}) \cup \mathrm{X}(\overline{\mathrm{HD}})$, and $\mathrm{G}^{\mathrm{H}}$ is an m-vector of differentiable functions. By observing and assigning $\mathrm{X}(\mathrm{H})$ for two years, s and t, we can use (3.3) to estimate percentage changes over the interval $[s, t], x_{s t}(\bar{H})$, in the variables in $X(\bar{H})$. Thus we combine a large amount of disaggregated information on the economy (the movements in the variables in $\mathrm{X}(\mathrm{H})$ ) with a CGE model to estimate movements in a wide variety of technological and preference variables $(\mathrm{X}(\overline{\mathrm{HD}}))$, together with movements in more standard endogenous variables $(\mathrm{X}(\overline{\mathrm{HD}}))$.

Next we move to the decomposition closure which gives a solution of the form

$$
\mathrm{X}(\overline{\mathrm{D}})=\mathrm{G}^{\mathrm{D}}(\mathrm{X}(\mathrm{D}))
$$

Following the method pioneered by Johansen (1960), we can express (3.4) in log-differential or percentage change form as

$$
x(\bar{D})=B x(D)
$$

where $x(\bar{D})$ and $x(D)$ are vectors of percentage changes in the variables in $X(\bar{D})$ and $X(D)$, and $B$ is an $m$ by $(n-m)$ matrix in which the ij-th element is the elasticity of the i-th component of $X(\bar{D})$ with respect to the $\mathrm{j}$-th component of $\mathrm{X}(\mathrm{D})$, that is 


$$
B_{i j}=\frac{\partial G_{i}^{D}(X(D))}{\partial X_{j}(D)} \frac{X_{j}(D)}{X_{i}(\bar{D})} .
$$

With the completion of the historical simulation, the percentage changes in all variables are known. In particular the vector $x(D)$ is known. Thus we can use (3.5) to compute values for $x(\bar{D})$ over the period s to t.

Our reason for working with (3.5) rather than (3.4) is that (3.5) can be used to give a decomposition of the percentage changes in the variables in $X(\bar{D})$ over the period s to $t$ into the parts attributable to movements in the variables in $X(D)$. This is a legitimate decomposition to the extent that the variables in $\mathrm{X}(\mathrm{D})$ are genuinely exogenous, that is, can be thought of as varying independently of each other. In setting up the decomposition closure, the exogenous variables are chosen with exactly this property in mind. Thus, in $\mathrm{X}(\mathrm{D})$ we find policy variables, technology variables, taste variables and international variables (e.g. foreign currency prices) all of which can be considered as independently determined and all of which can be thought of as making their own contributions to movements in endogenous variables such as incomes, consumption, exports, imports, outputs, employment and investment. Equation (3.5) provides one way to compute these contributions. Via (3.5), we can compute the contribution of the percentage movement in the jth exogenous variable to the percentage movement in the ith endogenous variable as

$$
\text { cont }_{\mathrm{ij}}=\mathrm{B}_{\mathrm{ij}} * \mathrm{x}_{\mathrm{j}}(\mathrm{D}) \text {. }
$$

Because (3.4) is a non-linear system, the effect on endogenous variable i over the period s to t of movements in exogenous variable $\mathrm{j}$ cannot be computed unambiguously. The problem is that in non-linear systems the effects of movements in any exogenous variable depend on the values adopted for other exogenous variables. In terms of (3.7), the problem is to decide at which values of the exogenous variables to evaluate $B_{\mathrm{ij}}$. The most natural choice is to use mid-point values, $\mathrm{B}^{\text {mid }}$, i.e., to evaluate the elasticities defined in (3.6) with $\mathrm{X}(\mathrm{D})$ set at approximately $0.5^{*}\left(\mathrm{X}_{\mathrm{s}}(\mathrm{D})+\mathrm{X}_{\mathrm{t}}(\mathrm{D})\right)$. As explained in Dixon and Rimmer (2002, section 22), in MONASH applications we evaluated $\mathrm{B}^{\text {mid }}$ using a database generated by an historical simulation in which the exogenous variables were moved from their values in year $s$ halfway to their values in year $t$. Subsequent to our MONASH decomposition simulations, Ken Pearson and his colleagues [Harrison et al. (2000)] have automated in GEMPACK a procedure which in effect evaluates $B^{\text {mid }}$ as the average of the values of the $B$ matrices generated as we move the exogenous variables in a decomposition simulation in small steps along a straight line from their values in year s to their values in year $t$. The decomposition analysis in section 5 uses Pearson's procedure. 


\section{Historical simulation for 1992 to 1998}

Table 4.1 indicates the partitioning of variables adopted for our 1992-1998 historical simulation together with data sources. Here we discuss each of the swaps between $\mathrm{X}(\mathrm{H} \overline{\mathrm{D}})$ and $\mathrm{X}(\overline{\mathrm{H}} \mathrm{D})$ and describe our results for preference, technology and trade-shift variables.

\section{Private consumption}

The first vector of variables in the Table 4.1 is private consumption by commodity, x3(i). This variable is normally explained in CGE models but can be observed. Thus it is a member of $\mathrm{X}(\mathrm{H} \overline{\mathrm{D}})$. To understand the choice of corresponding variable in $\mathrm{X}(\overline{\mathrm{H}} \mathrm{D})$, we need to look at the equations in USAGE_ITC explaining household demand by commodity.

These equations take the form:

$$
\begin{aligned}
& \mathrm{x}_{3}(\mathrm{i})-\mathrm{q}=\varepsilon(\mathrm{i}) *(\mathrm{c}-\mathrm{q})+\sum_{\mathrm{k}} \eta(\mathrm{i}, \mathrm{k}) * \mathrm{p}_{3}(\mathrm{k})+\left[\mathrm{a} 3 \operatorname{com}(\mathrm{i})-\mathrm{a} 3 \operatorname{com} \_ \text {ave }\right], \quad \mathrm{i}=1, \ldots, \mathrm{N} \\
& \mathrm{a} 3 \mathrm{com} \_ \text {ave }=\sum_{\mathrm{k}} \mathrm{S}_{3}(\mathrm{k}) * \mathrm{a} 3 \operatorname{com}(\mathrm{k})
\end{aligned}
$$

and

$$
\mathrm{c}=\mathrm{apc}_{\text {gnp }}+\mathrm{gnp},
$$

where

$\mathrm{x}_{3}(\mathrm{i})$ is the percentage change between two years in private consumption of commodity $\mathrm{i}$; $\mathrm{q}$ is the percentage change in the number of households;

$\varepsilon(i)$ is the expenditure elasticity of demand by households for commodity $i$;

$\mathrm{c}$ is the percentage change in aggregate expenditure by households;

$\eta(i, k)$ is the elasticity of demand for commodity $i$ with respect to changes in the price of $k$;

$\mathrm{p}_{3}(\mathrm{k})$ is the percentage change in the price to households of commodity $\mathrm{k}$;

$\mathrm{S}_{3}(\mathrm{k})$ is the share of commodity $\mathrm{k}$ in household expenditure;

a3com(i) is a commodity-i preference variable;

a3com_ave is a budget-share-weighted average of the a3com $(\mathrm{k}) \mathrm{s}$;

$\mathrm{apc}_{\mathrm{gnp}}$ is the percentage change in the average propensity to consume out of GNP; and gnp is the percentage change in GNP. 


\section{Table 4.1. Categories of Variables in the Historical and Decomposition Closures}

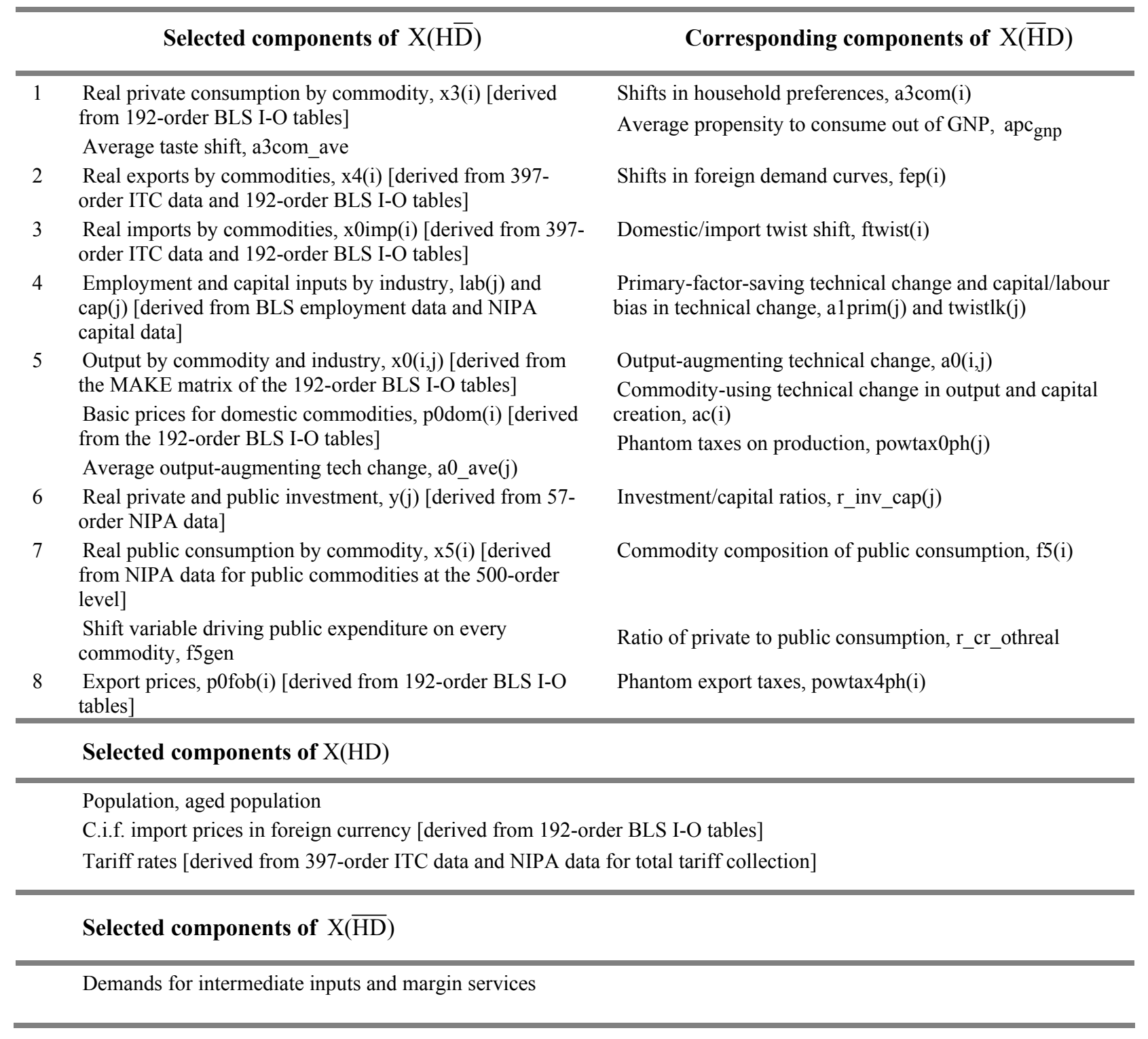

If a3com(i) is 1 greater than the a3com_ave, then the rate of growth of consumption per household of commodity $\mathrm{i}$ is 1 percentage point higher than would be expected on the basis of changes in total expenditure per household and changes in prices. Without the inclusion of a3com_ave on the RHS of (4.1), there is a danger of violating the budget constraint. ${ }^{2}$

${ }^{2}$ With $\varepsilon(\mathrm{i})$ and $\eta(\mathrm{i}, \mathrm{k})$ satisfying the standard properties (see Dixon et al., 1980, pp. 90-97) of expenditure and price elasticities derived from a utility maximizing model, (4.1) implies that $\sum_{\mathrm{i}}\left[\mathrm{p}_{3}(\mathrm{i})+\mathrm{x}_{3}(\mathrm{i})\right]^{*} \mathrm{~S}_{3}(\mathrm{i})=\mathrm{c}$. If a3com_ave were omitted from the RHS of (3.1) then this condition would not necessarily be satisfied. 
In the decomposition closure, (4.1) to (4.3) are implemented with a3com(i) and apc gnp as exogenous variables ${ }^{3}$ and with $\times 3$ (i) and a3com_ave as endogenous variables. Preference changes and the average propensity to consume are not normally explained in USAGE-ITC. Movements in consumption on the other hand are explained and, with the a3com(i)s exogenous, a3com_ave must be endogenous. In the historical simulation, information on movements in consumption by commodity is introduced to contribute to the estimation of changes in household preferences and in the average propensity to consume. We, in effect, ${ }^{4}$ exogenize the $x_{3}(i) s$ and shock them with their observed movements between 1992 and 1998. To allow the exogenous $\mathrm{x}_{3}(\mathrm{i}) \mathrm{s}$ to be consistent with (4.1) to (4.3) we endogenize the a3com(i)s and $a p c_{\text {gnp. }}$. Endogenization of the a3com(i)s requires exogenization of a3com_ave. ${ }^{5}$ Otherwise, the absolute level of the movements in the a3com(i)s would be indeterminate. Exogenization of the $\mathrm{x} 3(\mathrm{i}) \mathrm{s}$ requires endogenization of apc $\mathrm{gnp}_{\text {gn }}$. Otherwise, there would be a potential inconsistency between the movement in aggregate consumption [determined largely by the x3(i)s] and GNP. With these exogenous/endogenous choices, x3(i) and a3com_ave are members of the set $X(H \bar{D})$. The corresponding members of $X(\overline{H D})$ are a3com(i) and apc ${ }_{g n p}$.

Results for the a3com(i)s from our 1992-1998 simulation can be deduced from columns 1 and 10 in Table 4.2. Column 1 shows the contribution of a3com(i) to growth in US output of commodity i. This contribution is calculated as

$$
\mathrm{c}_{-} \mathrm{a} 3 \operatorname{com}(\mathrm{i})=\frac{\mathrm{BAS} 3(\mathrm{i}, \mathrm{dom})}{\mathrm{SALES}(\mathrm{i})} *\left[\mathrm{a} 3 \operatorname{com}(\mathrm{i})-\mathrm{a} 3 \mathrm{com} \_ \text {ave }\right]
$$

where SALES(i) and BAS3(i,dom) are the basic values of US output of commodity $i$ and of sales of US commodity $i$ to households. Column 10 shows consumption to sales ratios: BAS3(i,dom)/SALES(i).

Many trends in US household behavior can be seen in column 1. For example, we can see evidence of increasing interest in health and lifestyle issues. The results in column 1 quantify the

3 Rather then exogenizing apc $_{\text {gnp }}$ we could exogenize the average propensity to consume out of household disposable income.

4 For many variables, our 1992-1998 observations are on different classifications from those used in USAGEITC. For example, our observations for private consumption are at the BLS 192-order input-output level. In USAGE-ITC we define the observed concept (e.g. consumption by BLS 192-order commodity) and apply the observed shocks directly to the relevant variable. Mapping of the observed shocks to the detailed USAGE-ITC classifications is handled in the model. As explained in section 6, observations on variables (e.g. imports) for which data are available at a highly disaggregated level help to inform estimates at that level of movements in other variables (e.g. consumption).

5 What we wish to determine in an historical simulation for each $\mathrm{i}$ is the taste shift given by a3com(i) a3com_ave. The value of this taste shift is independent of the value chose for a3com_ave. It is convenient to set a3com_ave at zero. 
strong shift in household preferences against tobacco products and alcohol. Cigarettes (Commodity 98), TobaccoSnuff (100), Malt beverages (82), Wine and spirits (84), and Distilled liquors (85) all appear with large negative entries. Lifestyle items such as Boatbuilding (360), Luggage (209), Travel trailer (363), Sporting clubs (456) and Cable TV (408) all have positive entries. Fashion changes leave Bowling centers (453) and Newspapers (162) with negative entries.

At this stage in the development of USAGE-ITC, we have not introduced empirically-based estimates of household expenditure elasticities, $\varepsilon(i)$. Instead, we have assumed that these all have the value one. Between 1992 and 1998, real consumer spending per household increased in the US by 12 per cent. Thus, if $\varepsilon(\mathrm{i})$ is more than one, our present estimate of a3com(i) overstates the shift in preferences towards the commodity. If $\varepsilon(i)$ is less than one, our present estimate of a3com(i) overstates the shift in preferences against the commodity. This bias could underlie the negative entries in column 1 for food items such as Fruit (10), Vegetables (12), Meat products (52 to 54) and Dairy products (56 to 59). These food items may have expenditure elasticities well below one. As part of the USAGE-ITC project we plan to estimate the $\varepsilon(\mathrm{i}) \mathrm{s}$ econometrically.

\section{Exports}

For most commodities, the export-demand equation in USAGE-ITC has the form

$$
x_{4}(i)=\exp \_ \text {elast }(i) *[p e(i)-f e p(i)]
$$

where

$\mathrm{x}_{4}$ (i) is the percentage change between two years in exports of commodity $\mathrm{i}$;

pe(i) is the percentage change in the f.o.b. foreign-currency price ${ }^{6}$ of US exports of commodity $i$;

exp_elast(i) is the foreign price elasticity of demand for US exports of commodity i (set at -3 for all i); and

fep(i) is the percentage vertical movement in the foreign demand curve for exports of $i$ from the US.

If fep(i) is 10 , this means that the US can maintain an unchanged level of exports of commodity $i$ with a 10 per cent increase in price.

As implied in row 2 of Table 4.1, fep(i) is naturally exogenous. Single country CGE models such as USAGE-ITC do not explain the positions of foreign demand curves. On the other hand, export volumes are naturally endogenous. For our historical simulation we have observations on the movements in export volumes [x4(i)]. We reconcile these with (4.5) by endogenizing the fep(i)s, that is we allow the historical simulation to generate estimates of the vertical shifts in the export demand curves. Thus, $x 4(i)$ is in the set $X(H \bar{D})$ and fep(i) is the corresponding variable in the set $X(\overline{H D})$.

\footnotetext{
${ }^{6}$ In USAGE-ITC, f.o.b. prices include US-supplied international shipping and air transport.
} 
Column 4 of Table 4.2 shows the contributions of the fep(i)s to growth in US output by commodity. These contributions were calculated as

$$
c_{-} \text {fep }(\mathrm{i})=-\frac{\mathrm{BAS} 4(\mathrm{i})}{\mathrm{SALES}(\mathrm{i})} *\left[\exp _{-} \operatorname{elast}(\mathrm{i}) * \text { fep }(\mathrm{i})\right]
$$

They give the percentage effects on US outputs of the movements in export demand curves, assuming no change in foreign currency prices.

For most commodities, the movement in the export demand curve between 1992 and 1998 made a positive contribution to US output growth. The major exceptions are the computer commodities (316 to 319). For these commodities there were sharp downward movements in foreign demand curves. With world prices of computers plummeting, the historical simulation shows that if US export prices had been held constant, then US output would have been severely reduced.

For some commodities, the entry in column 4 is very high, well in excess of the increase in US output. An example is Export tourism, commodity 499. The output of this commodity is entirely exported and consists of holidays in the US for foreigners. If there had been no change in the price of these holidays, then the US output of commodity 499 would have increased by 84.13 per cent. The actual increase was only 29.15 per cent. The upward shift in the export demand curve for holidays in the US was offset to a large extent by an increase in their foreign currency price.

\section{Imports}

USAGE-ITC uses the Armington specification of import/domestic choice [Armington 1969, 1970]. For the typical agent $\mathrm{k}$ (e.g. consumers and industries) the percentage change in the ratio of import to domestic usage of commodity $i$ is given by:

$$
x m(i)^{\mathrm{k}}-x d(i)^{\mathrm{k}}=-\sigma(\mathrm{i})^{\mathrm{k}} *\left[\operatorname{pm}(\mathrm{i})^{\mathrm{k}}-\operatorname{pd}(\mathrm{i})^{\mathrm{k}}\right]+\operatorname{twist}(\mathrm{i}),
$$

where

$\mathrm{xm}(\mathrm{i})^{\mathrm{k}}$ and $\mathrm{xd}(\mathrm{i})^{\mathrm{k}}$ are percentage changes in the demand for imported and domestically produced good $\mathrm{i}$ by agent $\mathrm{k}$;

$\operatorname{pm}(\mathrm{i})^{\mathrm{k}}$ and $\operatorname{pd}(\mathrm{i})^{\mathrm{k}}$ are percentage changes in the prices to agent $\mathrm{k}$ of imported and domestically produced good i;

$\sigma(\mathrm{i})^{\mathrm{k}}$ is a positive parameter (k's elasticity of substitution between imported and domestically produced good i) that controls the responsiveness of the import/domestic mix to changes in relative prices $^{7}$; and

twist(i) is a variable allowing for cost-neutral changes in preferences between imported and domestically produced good i. Cost neutrality is imposed by including twist terms in the demand equations for both domestic and imported goods in such a way that these terms allow for the

\footnotetext{
7 The values of the Armington elasticities in USAGE-ITC are those used in the ITC's Import Restraints study of 2002.
} 
replacement of domestic goods with imported goods of equal cost to the user. Specifically, the twist terms are included in the USAGE-ITC demand equations as follows:

$$
\mathrm{xm}(\mathrm{i})^{\mathrm{k}}=\mathrm{SD}^{\mathrm{k}}(\mathrm{i}) * \text { twist }(\mathrm{i})+\text { price and activity var iables },
$$

and

$$
\mathrm{xd}(\mathrm{i})^{\mathrm{k}}=-\mathrm{SM}^{\mathrm{k}}(\mathrm{i}) * \text { twist }(\mathrm{i})+\text { price and activity variables , }
$$

where $\mathrm{SD}^{\mathrm{k}}(\mathrm{i})$ and $\mathrm{SM}^{\mathrm{k}}(\mathrm{i})$ are the shares of domestic and imported goods in agent k's expenditure on commodity i.

We model import/domestic twists as:

$$
\text { twist }(\mathrm{i})=[\mathrm{x} 0 \operatorname{dom}(\mathrm{i})-\mathrm{gdpreal}]+\mathrm{ftwist}(\mathrm{i})
$$

where

x0dom(i) is the percentage change in domestic output of commodity $i$;

gdpreal is the percentage change in real GDP; and

ftwist(i) is a shift variable.

The first term on the RHS of (4.7d) allows for demand pressures. It captures the idea that when output of commodity $\mathrm{i}$ in the domestic economy is growing rapidly, there is a tendency for demand shifts to occur towards imports. This is explained by shortages and lengthening queues and is unrelated to movements in relative prices. Similarly, when output of $\mathrm{i}$ is growing slowly there is a tendency for shifts to occur towards the domestic product. The second term allows for twists in import/domestic ratios beyond those that can be explained by changes in relative prices and demand pressures.

In decomposition simulations, imports are explained and ftwist(i)s are exogenous. For the historical simulation, we observed the movement in aggregate imports of commodity $i, x 0 \mathrm{imp}(i)$. We made this compatible with (4.7d) by endogenizing ftwist(i). Thus, the $x 0$ imp(i)s are part of the set $\mathrm{X}(\mathrm{H} \overline{\mathrm{D}})$ and the ftwist(i)s are the corresponding variables in $\mathrm{X}(\overline{\mathrm{H}} \mathrm{D})$.

Column 3 of Table 4.2 shows the percentage contributions of the twist-shifts [the ftwist(i)s] for the period 1992 to 1998 to sales in the US of domestic commodities. The contribution [c_ftwist(i)] for commodity i was calculated as the direct effect of ftwist(i) on sales in the US of domestically produced i: that is

$$
\text { c_ftwist }(\mathrm{i})=-\sum_{\mathrm{k}} \frac{\mathrm{BAS}^{\mathrm{k}}(\mathrm{i}, \operatorname{dom})}{\text { DOM_SALES(i) }} * \mathrm{SM}^{\mathrm{k}}(\mathrm{i}) * \mathrm{ftwist}(\mathrm{i})
$$

where

$\operatorname{BAS}^{\mathrm{k}}$ (i, dom) is the basic value of agent k's purchases of domestically produced $\mathrm{i}$; and

DOM_SALES(i) is the basic value of all sales in the US of domestically produced commodity $\mathrm{i}$.

The entries in column 3 for some commodities are large and negative, while for others they are large and positive. Overall there was a small twist in favor of imports, with the average effect on 
domestic sales of domestic products being -0.38 per cent. ${ }^{8}$ The Footwear commodities $(199,205,206$ and 207) are examples of products for which there were large twists towards imports [negative entries in column 3]. The computer commodities $(316,317,318$ and 319) are examples of products for which there were large twists against imports.

The size of the ftwist(i) contribution depends on the value adopted for the Armington elasticity $[\sigma(\mathrm{i})]$ and on our specification in (4.7d) of the demand-pressure effect. For both footwear and computer products, our historical simulation shows only minor differences between the movements in domestic and import prices. Consequently, for these products our measured values of the ftwist(i)s would not be sensitive to plausible variations in the values adopted for the Armington elasticities. However, variations in the demand-pressure specification may be important. Growth in US output of computer products was extremely rapid, about 500 per cent between 1992 and 1998. Under (4.7d), this implies a strong demand-pressure twist towards imports. It seems, at least for computers, that we may have allowed the demand-pressure effect to be too strong, requiring large movements in the ftwist(i)s in favor of domestically produced computer products. For footwear products, especially commodities 206 and 207, US output growth was well below GDP growth. In these circumstances, $(4.7 \mathrm{~d})$ gives demand-pressure twists in favor of domestic products. Again, this effect may have been overstated, leading to measured ftwist(i)s that are excessively unfavorable to domestic footwear production.

\section{Production and technological change}

A stripped-down version of the input and output equations in MONASH is

$$
\begin{aligned}
& \operatorname{lab}(j)=z(j)+a 1(j)+\operatorname{alprim}(j)-\theta(j) *\left[w(j)-p_{p f}(j)\right]+S_{K}(i) * \operatorname{twistlk}(j) \\
& \operatorname{cap}(j)=z(j)+a 1(j)+\operatorname{alprim}(j)-\theta(j) *\left[q(j)-p_{p f}(j)\right]-S_{L}(i) * \operatorname{twistlk}(j) \\
& x 1(i, j)=z(j)+a 1(j)+a c(i) \\
& x 0(i, j)=z(j)+\phi(j) *[p 0 \operatorname{dom}(i)-p 0 \operatorname{ind}(j)]+a 0(i, j)-a 0 \_a v e(j) \\
& a 0 \_a v e(j)=\sum_{i} H 0(i, j) * a 0(i, j)
\end{aligned}
$$

where

$\operatorname{lab}(\mathrm{j})$ is the percentage change in labor input to industry $\mathrm{j}$; cap $(\mathrm{j})$ is the percentage change in capital input to industry $\mathrm{j}$;

$z(j)$ is the percentage change in the overall level of output in industry $j$;

$w(j)$ is the percentage change in the wage rate paid in industry $j$;

$q(j)$ is the percentage change in the rental rate for units of capital in industry $j$;

$S_{K}(j)$ and $S_{L}(j)$ are capital and labor shares in the costs of capital and labor to industry $j$;

\footnotetext{
${ }^{8}$ A share-weighed average of the entries in column 3 using value-added weights [column 7] is -0.38.
} 
$\mathrm{p}_{\mathrm{pf}}(\mathrm{j})$ is the percentage change in the overall price of primary factors to industry $\mathrm{j}$ [a weighted average of $q(j)$ and $w(j)$ with $S_{K}(j)$ and $S_{L}(j)$ weights];

$\theta(\mathrm{j})$ is the elasticity of substitution in industry $\mathrm{j}$ between labor and capital [currently assumed to be 0.5 for all industries];

$\mathrm{x} 1(\mathrm{i}, \mathrm{j})$ is the percentage change in the input of good $\mathrm{i}$ to industry $\mathrm{j}$;

a1(j) is a variable allowing for all-input-using ${ }^{9}$ changes in industry $j$ 's technology;

alprim(j) is a variable allowing for primary-factor-using changes in industry $\mathrm{j}$ 's technology;

twistlk(j) is a variable allowing for cost-neutral twists ${ }^{10}$ in $\mathrm{j}$ 's technology either favoring labor (positive) or favoring capital (negative);

ac(i) is a variable allowing for i-using technical change in all industries;

$\mathrm{x} 0(\mathrm{i}, \mathrm{j})$ is the percentage change in the output of commodity $\mathrm{i}$ by industry $\mathrm{j}$;

$\mathrm{H} 0(\mathrm{i}, \mathrm{j})$ is the share of industry $\mathrm{j}$ 's revenue accounted for by commodity $\mathrm{i}$;

$\mathrm{a} 0(\mathrm{i}, \mathrm{j})$ is a variable allowing for commodity-i-output-augmenting technical change in industry $\mathrm{j}$;

a0_ave(j) is the average amount of commodity-output-augmenting technical change in industry $\mathrm{j}$ [a weighted average over i of the a0(i,j)s using the $\mathrm{H} 0(\mathrm{i}, \mathrm{j}) \mathrm{s}$ as weights;

$\phi(j)$ is the elasticity of transformation in industry $\mathrm{j}$ between the production of different commodities [currently assumed to be 2.0 for all industries];

p0dom(i) is the percentage change in the basic price (price received by producers net of taxes) of commodity i; and

$\mathrm{p} 0$ ind(j) is the percentage change in the industry price of output for industry $\mathrm{j}$ [a revenue-shareweighted average of the p0dom(i)s].

Equations (4.9) to (4.11) can be derived from an optimization problem in which inputs are chosen to minimize the cost of a specified overall level of output, treating input prices as given. In this optimization problem, the production function is Leontief in intermediate inputs and primary factors and CES in the primary-factor nest. Equation (4.12) can be derived from an optimization problem in which the commodity composition of output is chosen to maximize revenue obtainable at a specified overall level of output, treating output prices as given. In this optimization problem, the transformation frontier is CET. ${ }^{11}$

With one exception, the technology variables in (4.9) to (4.13) are exogenous in decomposition simulations. The exception is a0_ave(j). With the a0(i,j)s exogenous, (4.13) dictates that a0_ave(j) must be endogenous. As indicated in row (4) of Table 4.1, for the historical simulation we had observations for lab(j) and cap(j). To accommodate these observations, we endogenized primary-factor-using technical change [a1prim(j)] and the labor/capital twist [twistlk(j)]. We also had observations for output by commodity and industry [x0(i,j), row (5) Table 4.1]. To accommodate these observations we needed two types of technical change. First, we needed to give USAGE-ITC

\footnotetext{
${ }^{9}$ Input-saving technical change is negative input-using technical change.

10 The variable twistlk(j) causes a twist in j's labor/capital ratio that is independent of changes in wages and rentals: notice that $\operatorname{lab}(\mathrm{j})-\operatorname{cap}(\mathrm{j})=$ twistlk(j). Movements in twistlk(j) are cost-neutral because they do not affect $\mathrm{j}$ 's use of primary factors per unit of overall output. In the absence of primary-factor and all-input-using technical change $[a 1 p r i m(j)=a 1(j)=0]$, (4.9) and (4.10) imply that $S_{K}(j) * c a p(j)+S_{L}(j) * l a b(j)=z(j)$, irrespective of the value of twistlk(j).

${ }^{11}$ Details of the algebra underlying equations such as (4.9) to (4.13) can be found in Dixon and Rimmer (2002, section 17).
} 
freedom to make the observed movement in the commodity composition of j's output compatible with revenue-maximizing behavior. Second, we need to give USAGE-ITC freedom to make the observed movement in the output of commodity $i$ [a weighted average across $j$ of the $x 0(i, j) s]$ compatible with demands for commodity $i$.

To satisfy the first requirement, we endogenized the relative values for industry $\mathrm{j}$ of the $\mathrm{a} 0(\mathrm{i}, \mathrm{j}) \mathrm{s}$. We did this by endogenizing the $\mathrm{a} 0(\mathrm{i}, \mathrm{j}) \mathrm{s}$ and exogenizing a0_ave(j) on zero change. It is possible to rationalize observed levels of outputs and inputs by different combinations of input-using and output-augmenting technical change. Exogenization of a0_ave(j) avoids this indeterminacy, allowing values to be determined for technical changes [e.g. alprim(j)] that affect j's inputs per unit of activity $[\mathrm{z}(\mathrm{j})]$ and technical changes $[$ the $\mathrm{a} 0(\mathrm{i}, \mathrm{j}) \mathrm{s}]$ that affect $\mathrm{j}$ 's outputs per unit of activity.

To satisfy the second requirement, we endogenized a technical change variable [ac(i)] affecting the input of commodity i per unit of current production and capital creation in each industry. Where $\mathrm{i}$ is a margin commodity, ac(i) also affects the margin use of i per unit of commodity flow throughout the economy. With ac(i) endogenized, USAGE-ITC has the freedom to adjust aggregate demand for commodity $i$ so that it is in line with the observed aggregate supply. If observed supply of commodity $i$ is greater than simulated demand in USAGE-ITC with ac(i) on zero, then we assume that there was i-using technical change, i.e. we allow ac(i) to take a positive value.

We encountered two complications in using the historical simulation to estimate the technical change variables a0(i,j) and ac(i). First, in our initial attempts, we found indeterminacy between the $\mathrm{a} 0(\mathrm{i}, \mathrm{j}) \mathrm{s}$ and the commodity prices, p0dom(i). The problem is that a shift in the composition of industry outputs towards commodity i can be explained either by i-augmenting technical progress [positive values for $\mathrm{a} 0(\mathrm{i}, \mathrm{j})$ for all $\mathrm{j}$ ] or by an increase in the basic price of $\mathrm{i}$ [a positive value for p0dom(i)]. With endogenous ac(i)s allowing adjustment in demands, the indeterminacy between technical change and price could not be resolved satisfactorily via the specification in UAGE-ITC of the demand for commodity i. To solve the problem, we introduced information on commodity prices. As can be seen in row (5) of Table 4.1, we exogenized the p0dom(i)s and shocked them with their values for 1992 to 1998. With outputs and prices fixed exogenously, industry revenues are known. Costs in each industry are also largely tied down by our data on domestic and import prices. Thus it was necessary to endogenize a cost variable for each industry to reconcile movements in revenues and costs with the zero-pure-profits condition. As indicated in row (5) of Table 4.1, we chose to endogenize powtax $0 \mathrm{ph}(\mathrm{j})$ for all $\mathrm{j}$. This is the power (one plus the rate) of a "phantom" production tax. It affects j's costs in the same way as a production tax, but the "revenue" from the tax is not collected by the government. Results for powtax $0 \mathrm{ph}(\mathrm{j})$ can be viewed as indicators of pure profits. More mundanely, they may indicate tensions between our data on costs and revenues.

The second complication concerns cost effects of i-using technical change, that is the cost effects of the ac(i)s. We wish to avoid the conclusion that heavy users of commodities with positive 
ac(i)s experienced technological deterioration. Thus we allowed endogenous adjustment (not indicated in Table 4.1) of the a1(j)s to neutralize the cost effects of the ac(i)s. We assumed that iusing technical change in industry $\mathrm{j}$ [a positive ac(i)] was offset by all-input-saving technical change in industry $\mathrm{j}$ [a negative value for a1(j)].

Columns 2, 5 and 6 of Table 4.2 contain results for three variables associated with our estimation of technical changes. Column 5 shows technical change in the production of each commodity. For commodity i we define this as the increase in output that would take place because of technical change, holding constant all prices and the volumes of inputs to all industries. In the present context, technical change in the production of $i$ can be calculated as

$$
\mathrm{t}_{-} \text {change }(\mathrm{i})=\sum_{\mathrm{j}} \frac{\operatorname{MAKE}(\mathrm{i}, \mathrm{j})}{\operatorname{SALES}(\mathrm{i})} *\left[\left\{\mathrm{a} 0(\mathrm{i}, \mathrm{j})-\mathrm{a} 0_{-} \operatorname{ave}(\mathrm{j})\right\}-\mathrm{S}_{\mathrm{pf}}(\mathrm{j}) * \operatorname{alprim}(\mathrm{j})\right]
$$

where

$\operatorname{MAKE}(i, j)$ is the basic value of the output of commodity $i$ by industry $j$;

SALES(i) is the basic value of $i$ produced by all industries;

$\mathrm{a} 0(\mathrm{i}, \mathrm{j}), \mathrm{a} 0$ ave(j) and alprim(j) are as defined earlier; and

$S_{p f}(j)$ is the share of primary factors in j's costs.

To understand (4.14) we start by assuming that industry $\mathrm{j}$ is responsible for $\mathrm{x}$ per cent of the output of commodity i, i.e., MAKE(i,j)/SALES(i) $=x / 100$. A value of one for $a 0(i, j)-a 0 \_a v e(j)$, holding constant prices and inputs, generates an increase the output of $i$ in industry $j$ of one per cent and an increase in the economy's output of commodity $i$ of $x^{*}\left\{a 0(i, j)-a 0 \_a v e(j)\right\}$ per cent. This means that a value of one for $\mathrm{a} 0(\mathrm{i}, \mathrm{j})$-a0_ave(j) contributes $\mathrm{x}^{*}\left\{\mathrm{a} 0(\mathrm{i}, \mathrm{j})-\mathrm{a} 0 \_\right.$ave $\left.(\mathrm{j})\right\}$ to technical change in the production of commodity i. As recognized in (4.14), technical change in the production of commodity $\mathrm{i}$ also depends on input-using technical changes in industry $\mathrm{j}$. Under our various cost-neutrality assumptions [a1(j) cancelling out the ac(i)s and twistlk being cost neutral], all of the technical change that affects $j$ 's total inputs per unit of activity $[z(j)]$ is encapsulated in alprim(j). A value of -1 for alprim(j) reduces primary-factor inputs per unit of activity in industry $j$ by one per cent. This is equivalent to a reduction of $S_{p f}(j)$ per cent in $j$ 's total inputs per unit of activity. With $j$ 's total inputs held constant, j's activity increases by $S_{p f}(j)$ per cent. This generates an expansion of $S_{p f}(j)$ per cent in $\mathrm{j}$ 's output of commodity $\mathrm{i}$, contributing $\mathrm{x} * \mathrm{~S}_{\mathrm{pf}}(\mathrm{j})$ per cent to the economy's output of commodity i.

For 410 out of the 503 USAGE-ITC commodities, column 5 contains a non-negative entry indicating technical progress or at least an absence of technological regress. For 232 commodities technical progress was more than 5 per cent; for 66 commodities technical progress was more than 10 per cent; and for 8 commodities technical progress was more than 20 per cent. Five of the commodities for which there was very rapid technical progress were in the computer equipment area (commodities 316 to 319 and 345). Another precision equipment commodity exhibiting very rapid 
technical progress was watches (345). The other two commodities in the plus-20 group were Security brokers (419) and Household services (482). While the result for Security brokers is plausible, reflecting the introduction of computer-assisted transfers of financial securities, the result for Household services is curious. This commodity is mainly services provided in domestic residences by maids, child-carers, cooks, cleaners and gardeners. Our result showing rapid technical progress reflects a real output increase of 10 per cent in the BLS input-output tables between 1992 and 1998 combined with a reduction in hours worked of about 20 per cent in the BLS employment statistics. The interpretation of these statistics should be checked with the BLS.

For 93 commodities, column 5 contains a negative entry indicating an increase in input requirements per unit of output. In some cases this reflects peculiarities of our model. Consider, for example, Scrap (commodity 479). Over the period 1992 to 1998 there was a rapid increase in imports of scrap. This produced a sharp decrease in US output. We assumed a normal increase in the price of domestic scrap (12.45 per cent). With Scrap being a secondary product for many industries (and a primary product for none), USAGE-ITC accommodated the decrease in Scrap output by generating negative values for $\mathrm{a} 0$ (Scrap, $\mathrm{j}$ ) for almost all industries $\mathrm{j}$, thereby inducing transformation away from the production of Scrap. In other words, USAGE-ITC implied that it became increasingly difficult to produce Scrap.

In other cases, the negative entry in column 5 may reflect sluggish adjustment, especially of capital. For example, output and employment in Bowling centres (453) declined between 1992 and 1998 but our USAGE-ITC historical simulation implies that Bowling centre capital stock was almost constant.

Finally, there may be cases in which the increasing complexity (e.g. legal requirements and proliferating variety) of service provision in the US has led to increases in labor and capital requirements per unit of service provided. Possible examples include Child day care (472), Doctors and dentists (458), State and local government health (488), Vet services (462) and Freight forwarders (405).

Column 2 of Table 4.2 shows the contributions to growth in sales of US products of inputusing technical change in production, capital creation and margin provision. The contribution for iusing technical change is calculated according to:

$$
\begin{aligned}
& \text { c_ac(i) }= \\
& \frac{\sum_{\mathrm{j}}[\operatorname{BASl}(\mathrm{i}, \text { dom }, \mathrm{j}) *\{\operatorname{ac}(\mathrm{i})+\operatorname{al}(\mathrm{j})\}+\operatorname{BAS} 2(\mathrm{i}, \mathrm{dom}, \mathrm{j}) *\{\operatorname{ac}(\mathrm{i})+\mathrm{a} 2(\mathrm{j})\}]+\operatorname{MARG}(\mathrm{i}) * \operatorname{ac}(\mathrm{i})}{\operatorname{SALES}(\mathrm{i})}
\end{aligned}
$$


where

BAS1(i,dom,j) and BAS2(i,dom,j) are the basic values of US-produced commodity i used by industry $\mathrm{j}$ as an input to production and as an input to capital creation;

MARG(i) is the basic value of commodity $i$ used as a margin; ${ }^{12}$

SALES(i), ac(i) and a1(j) are as defined earlier; and

a2(j) is a variable allowing for all-input-using technical change in capital creation for industry $j$. Adjustments in a2(j) are used to neutralize the effects of the ac(i)s on costs per unit of output in capital creation in industry $\mathrm{j}$.

The outstanding winners from input-using technical change between 1992 and 1998 were the computer equipment products (316 to 319 ) and computer services (435). The use of computers per unit of output has grown rapidly throughout US industry and there is no doubt that computer-using technical change has played an important role. By adopting Leontief assumptions for intermediate inputs, we have assumed that computer use per unit of output has not been affected by the sharp reduction in the price of computers. To the extent that this price reduction has stimulated computer use, the computer entries in column 2 overestimate the effect of computer-using technical change. However, this overestimate may not be serious. For consumers, where we allowed for price sensitive choice between commodities, the preference shifts in favor of computers [the a3com(i)s] were of similar magnitudes to the ac(i)s. The contributions shown in column 1 of Table 4.2 for computer products are small relative to those in column 2 mainly because the household sales shares for the computer commodities (316 to 319,435$)$ are small relative the intermediate and investment sales shares [compare the computer entries in column 10 of Table 4.2 with those in columns 8 and 9].

Another group of commodities for which output growth has been strongly stimulated by commodity-using technical change are various types of business services e.g. Personnel supply (434), Job training (471), Management services (440) and Other business services (439).

Reflecting an apparent shift in Defence priorities, Tanks (48) and Guided missiles (46) appear in column 2 with large positive entries while Small arms ammunition (50), Ammunition (47), Small arms (49) and Ordnance (51) appear with large negative entries. Other interesting contrasts in column 2 can be seen in the entries relating to construction. Between 1992 and 1998 we find shifts against the use of Glass (213), Sawmill products (127), Wood fixtures (148), Fixtures excluding wood (149), Brick and clay tiles (216), Structural clay products (219) and Clay Refractories (218). On the other hand, there were shifts in favor of the use of Concrete products (226), Ready-mix concrete (227), Concrete bricks (225) and Cement (215).

The final pair of commodities that we will consider here are Water transport (402) and Water exports (502). Water transport consists of water transport services provided in the US. Water exports consists of water transport services outside the US provided by US ships. Intermediate usage of these

\footnotetext{
${ }^{12}$ In USAGE-ITC, all margins services are produced domestically.
} 
services is almost entirely for transport of freight. The large negative entries in column 2 for commodities (402) and (502) may reflect two factors: improvements in container packing procedures and miniaturization of products such as computers. Both these factors have the effect of reducing water transport services per unit of freight.

Column 6 of Table 4.2 contains the results from the historical simulation for the powtax $0 \mathrm{ph}(\mathrm{j}) \mathrm{s}$ converted to commodity concepts according to:

$$
p h \_c o m(i)=\sum_{j} \frac{\operatorname{MAKE}(i, j)}{\operatorname{SALES}(i)} * \operatorname{powtax} 0 \operatorname{ph}(j) .
$$

The average of the absolute values of the entries in column 6 is seven per cent. This is a measure of the overall level of tension between our commodity/industry data on costs and prices.

For 240 commodities, our cost and price data seem highly compatible, with ph_com(i) lying in the interval -5 to +5 . However, for some commodities the ph_com(i)s have large absolute values. The largest are for the computer equipment commodities (316 to 319). The industries producing these commodities experienced extremely rapid multi-factor productivity growth [column 5]. However, the declines in their selling prices were even more rapid. These statistics imply that the computer product industries suffered sharp reductions in profitability. These reductions are reflected in USAGE-ITC by large "phantom" subsidies which allow the model to reconcile prices and costs. At the opposite extreme we find Funeral services (427). The positive value of ph_com(i) for this commodity is consistent with sharply increased profitability in the Funeral business. Another group of industries that appear to have gained in profitability are those producing tobacco commodities ( 9 and 98 to 101). An unintended effect of increasing tobacco regulation (e.g. restrictions on advertising expenditures) may be profit enhancement through reduced competition.

\section{Investment by industry}

USAGE-ITC contains equations defining movements in investment/capital ratios. These take the form:

$$
r_{-} \text {inv_cap }(j)=y(j)-c a p \_a t \_t(j) .
$$

where

r_inv_cap(j) is the percentage change between two years in the ratio of real investment to the quantity of capital used in industry $\mathrm{j}$ (industry j's start-of-year capital stock);

$y(j)$ is the percentage change in investment in industry $j$; and

cap_at_t $(j)$ is the percentage change in $j$ 's start-of-year capital stock.

In the decomposition closure, cap_at_t $(j)$ is endogenous and is determined mainly by assumptions concerning rates of return, $r_{-}$inv_cap(j) is exogenous and $y(j)$ is endogenous and is determined by (4.17). In the historical simulation we introduced information on the $y(j) s$. Thus they became exogenous and the r_inv_cap(j)s became endogenous. 
Between 1992 and 1998, investment in most industries grew rapidly relative to their capital stock. Consequently, for most industries our historical simulation generated a strongly positive value for r_inv_cap(j).

\section{Real public consumption}

Real public consumption by commodity is specified in USAGE-ITC as:

$$
\mathrm{x} 5(\mathrm{i})=\mathrm{f} 5(\mathrm{i})+\mathrm{f} 5 \mathrm{gen} \quad \text { for all commodities } \mathrm{i}
$$

where

$\mathrm{x} 5(\mathrm{i})$ is the percentage change between two years in public consumption of commodity $\mathrm{i}$; and

f5(i) and f5gen are variables allowing for shifts in the commodity composition of public consumption and for overall changes in the level of public consumption.

USAGE-ITC also defines the percentage change in the ratio of real private to real public consumption as:

$$
r_{-} \text {cr_othreal }=\mathrm{cr}-\text { othreal } \quad \text { for all commodities } \mathrm{i}
$$

where

cr and othreal are the percentage changes between two years in real private consumption and real private consumption.

In the decomposition closure, the commodity composition of public consumption is exogenous and the overall quantity of public consumption is endogenous, and linked to the overall quantity of private consumption. Thus, the f5(i)s and $r_{-}$cr_othreal are exogenous and f5gen and othreal are endogenous. (Real private consumption is determined elsewhere, by movements in real GNP.) In the historical simulation we introduce information on real public consumption by commodity, the $\mathrm{x} 5(\mathrm{i}) \mathrm{s}$. To accommodate this information, we exogenize the $\mathrm{x} 5$ (i)s and endogenize the f5(i)s. With the x5(i)s known, aggregate public consumption can no longer be exogenously linked to private consumption. Consequently, r_cr_othreal is endogenized. Correspondingly, f5gen is exogenized.

Because public consumption declined relative to private consumption between 1992 and 1998, our historical simulation generated a positive value for $r_{-}$cr_othreal. The values for the f5(i)s in the historical simulation revealed a realignment of public expenditure against National Defense and State and Local Government Health, and in favor of State and Local Government Education, State and Local Government Welfare and State and Local Government Police. 


\section{Export prices}

USAGE-ITC relates domestic currency f.o.b. export prices to costs and export taxes via zeropure-profit conditions in exporting. In decomposition simulations, export prices are endogenous and rates of export taxes are exogenous. For our historical simulation, we introduced information on movements in export prices, requiring exogenization of these prices. To reconcile exogenous export prices with zero pure profits in exporting, we endogenize phantom export taxes. Between 1992 and 1998 export prices did not increase by as much as would be expected on the basis of movements in costs. Thus the historical simulation generated negative phantom export taxes. This is consistent with outward movements in US export supply curves, possibly reflecting increasing awareness by US firms of export opportunities.

\section{Decomposition simulation for 1992 to 1998}

Having completed the historical simulation, we now adopt the decomposition closure in which technology and taste variables [e.g. a3com, ftwist, twistlk, a 0 and ac] are exogenous. By setting these variables at their values estimated from the historical simulation, we obtain results in the decomposition simulation for output, employment and other endogenous variables identical to those in the historical simulation. However, with technology and tastes exogenous in the decomposition simulation we can answer questions about the effects of changes in these variables. More generally, we can decompose history into the parts attributable to changes in variables such as those identified in the column headings of Tables 5.1 and 5.2.

We present the decomposition analysis in four subsections. The first provides necessary background on the macroeconomic assumptions underlying the decomposition simulation. The second explains the macro results in Table 5.1, column by column. In the third we look across the columns of Table 5.1 to provide a case study on the factors underlying growth in US trade. Finally, in the fourth subsection we work through a case study for the iron and steel sector drawing on results for industry and commodity outputs (see Table 5.2).

\subsection{Macroeconomic assumptions in the decomposition simulation}

For understanding the results in Tables 5.1 and 5.2, it is useful to first work through Figure 5.1. This is a flow diagram for a one-commodity CGE model. Consequently it does not illustrate relative-price or other structural effects. While these are important, Figure 5.1 is, nevertheless, a helpful representation of the main macro assumptions underlying our USAGE-ITC decomposition simulation.

Exogenous variables in the decomposition closure are represented in Figure 5.1 by rectangles while endogenous variables are shown in ovals. The change in aggregate employment between 1992 
and $1998(\Delta \mathrm{L})$, for example, is exogenous. Thus we assume that changes in technology $(\Delta \mathrm{TECH})$ and changes in other exogenous variables between 1992 and 1998 did not effect aggregate employment in 1998. As is conventional in macro modelling, we assume that employment effects are eliminated over the medium term by adjustments in wage rates.

Lines (1), (2) and (3) in Figure 5.1 impose a production function: the change in output ( $\triangle \mathrm{GDP}$ ) between 1992 and 1998 is a function of $\triangle \mathrm{TECH}, \Delta \mathrm{L}$ and the change in start-of-year capital $(\Delta \mathrm{K})^{13}$.

We assume that capital earns the value of its marginal product, that is, MPK is the ratio of the rental price of capital to the price of the product. In a one-commodity model, the product price can represent the asset price of capital. Consequently, MPK is the ratio of the rental price of capital to the asset price. We represent the rental/asset price ratio as the rate of return (ROR). Under constantreturns-to-scale (assumed in USAGE-ITC), MPK is a function of $\mathrm{K} / \mathrm{L}$ and TECH. Thus, $\triangle \mathrm{K}$ is determined by $\Delta \mathrm{L}, \Delta \mathrm{TECH}$ and $\triangle \mathrm{ROR}$ [lines (4), (5) and (6)].

${ }^{13}$ We assume that GDP in any year is a function of technology available during the year, labour used during the year and capital available at the start of the year. In the present context $\Delta \mathrm{K}$ is the change in the capital stock between the start of 1992 and the start of 1998. 


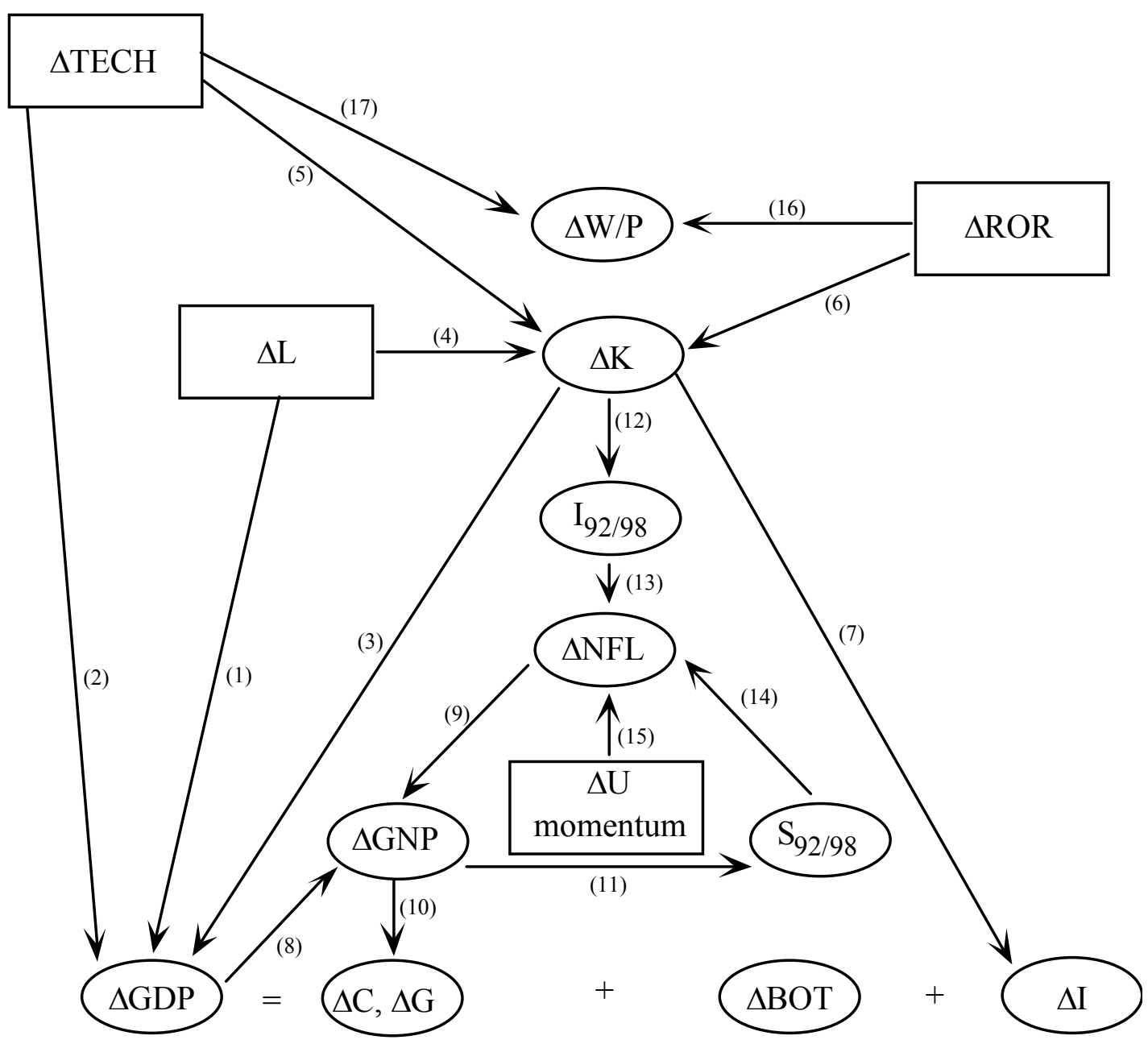

As indicated in the figure, in our decomposition simulation $\triangle \mathrm{ROR}$ is exogenous. When we are concerned with analyzing the effects of particular shocks over periods as long as six years (1992 to 1998) it is conventional to assume that capital adjusts to restore rates of return. For example, in isolating the effects of technology changes between 1992 and 1998, we assume that rates of return are unaffected, i.e. $\triangle \mathrm{ROR}=0 .{ }^{14}$

With capital earning the value of its marginal product, labour also is paid according to the value of its marginal product. Thus, via the factor-price frontier (the relationship between the MPK, MPL and TECH, Samuelson, 1962), $\triangle \mathrm{ROR}$ and $\triangle \mathrm{TECH}$ determine the real wage rate. This is indicated in Figure 5.1 by lines (16) and (17).

${ }^{14}$ In practice we have found it useful to damp capital responses in individual industries by introducing a positive relationship between capital growth and required rates of return. Thus, in USAGE-ITC decomposition simulations it is only the average rate of return across industries that is treated exogenously. 
Exogenization of the rate of return can be thought of as tying down capital stocks in 1998. While tying down capital stocks for 1998 ties down aggregate investment between 1992 and 1998, it does not determine investment in 1998. We link investment in 1998 to capital in 1998 [line (7) in Figure 5.1]. In isolating the effects of changes in technology etc., we assume that such changes have no impact on business confidence. Thus we treat the investment/capital ratio (a reflection of business confidence) as exogenously determined.

Lines (8) and (9) allow for the calculation of the change in gross national product between 1992 and 1998 ( $\Delta$ GNP). This is $\Delta$ GDP less the change in net interest/dividend payments to foreigners (a proportion of the change in start-of-year net foreign liabilities, $\Delta \mathrm{NFL}$ ). ${ }^{15}$

We assume in line (10) that the changes in private and public consumption $(\Delta \mathrm{C}, \Delta \mathrm{G})$ are exogenously given proportions of the change in GNP. With $\Delta \mathrm{GDP}, \Delta \mathrm{C}, \Delta \mathrm{G}$ and $\Delta \mathrm{I}$ now determined, the change in the balance of trade $(\triangle \mathrm{BOT})$ falls out as a residual.

Line (11) links accumulated excess savings $\left(\mathrm{S}_{92 / 98}\right)$ to $\Delta \mathrm{GNP}$. $\mathrm{S}_{92 / 98}$ is the difference between the value of accumulated saving over the period 1992 to 1998 and the value it would have had in the absence of any change over this period in GNP. In deriving the link between $\mathrm{S}_{92 / 98}$ and $\Delta \mathrm{GNP}$, we assume that saving in each year between 1992 and 1998 is a fixed proportion of GNP. Under a smooth growth assumption applied to GNP, this allows us to specify accumulated excess saving as a function of $\triangle \mathrm{GNP}$.

By again invoking a smooth growth assumption, we can specify in our model the excess accumulated cost of investment $\left(\mathrm{I}_{92 / 98}\right)$ between the beginning of 1992 and the beginning of 1998 in terms of the change between these two dates in the capital stock $(\Delta K)$. The excess cost of investment is the difference in the value of accumulated investment and the value it would have had in the absence of any change over the period in the aggregate capital stock. The link between $\mathrm{I}_{92 / 98}$ and $\Delta \mathrm{K}$ is indicated in Figure 5.1 by line (12).

The final set of relations in Figure 5.1 are lines (13), (14) and (15). They determine $\triangle$ NFL as a combination of three components: $\mathrm{I}_{92 / 98}$ minus $\mathrm{S}_{92 / 98}$ plus momentum (denoted by $\Delta \mathrm{U}$ ). Momentum is the change in NFL which would have occurred in the absence of either excess accumulated savings or excess accumulated investment, that is the change in NFL that would have occurred in the absence of changes in GNP and K. Momentum consists of accumulated interest payments between 1992 and 1998 on the net foreign liabilities of 1992 plus depreciation investment (that is the investment required to maintain the capital stock at its 1992 level) minus static saving (that is the accumulated value of saving that would have occurred in the absence of any change in GNP). 


\subsection{Decomposition simulation: macro results}

The last column of Table 5.1 shows outcomes for macro variables for the US between 1992 and 1998. Columns 1 through 10 provide a decomposition of these outcomes computed according to (3.5) with the closure illustrated in Figure 5.1.

The outstanding feature of the period 1992 to 1998 was rapid growth in trade relative to GDP. Whereas the increase in real GDP was 20.45 per cent, export and import volumes increased by 47.45 and 67.76 per cent. Our decomposition tables can be used to explain this increase in trade as a share of GDP as well as many other developments in the US economy.

In analysing the decomposition results, we start by looking at each of the columns 1 to 10 individually. Then, in our first case study, we look across the columns to identify the major determinants of growth in US trade.

\section{Column 1: momentum}

Column 1 in Table 5.1 shows momentum effects, i.e. what would have happened to the US economy over the period 1992 to 1998 if there had been no changes in other exogenous variables, that is no changes in the variables identified in the headings to columns 2 through 10.

With $\triangle \mathrm{L}, \triangle \mathrm{TECH}$ and $\triangle \mathrm{ROR}$ fixed at zero in the momentum column, Figure 5.1 indicates that there should be no change in K, I and GDP. That there are small changes in I and GDP and a larger change in $\mathrm{K}$ reflects structural effects which cannot be captured in a one-commodity representation of USAGE-ITC. These structural effects will be discussed shortly.

Consistent with Figure 5.1, column 1 of Table 5.1 shows a large effect for NFL, with significant consequences for GNP, $\mathrm{C}$ and $\mathrm{G}$ (see rows 2, 10, 11 and 12 ) ${ }^{16}$. With almost no growth in $\mathrm{K}$ between 1992 and 1998 (1.8 per cent over six years, row 6), investment expenditures over the period would have covered little more than depreciation. In these circumstances, US saving would have outstripped investment expenditures leading to a decline in NFL relative to GDP (14.32 per cent, row 2, column 1). This would have allowed an increase in GNP, C and G (0.84, 0.82 and 0.77 per cent,

15 GNP $=$ GDP - ROI*NFL where ROI is the rate of interest or dividend on net foreign liabilities. Holding ROI constant, we obtain: $\triangle \mathrm{GNP}=\Delta \mathrm{GDP}-\mathrm{ROI} * \Delta \mathrm{NFL}$.

16 In the decomposition closure, nominal consumption (private plus public) is an exogenous fraction of nominal GNP. This fraction is fixed in all columns of Table 5.1 except column 10. Discrepancies in columns 1 to 9 between the results for $\mathrm{C}$ plus G and real GNP are caused mainly by differences in the deflators for consumption and for GNP. In all columns the ratio of $\mathrm{C}$ to $\mathrm{G}$ is exogenous. It is fixed on zero change in columns 1 to 9 and shocked in column 10. Nevertheless, there are discrepancies between the percentage change results for $\mathrm{C}$ and $\mathrm{G}$ (rows 11 and 12) in columns apart from 10. While, in any column apart from 10, the changes in $\mathrm{C}$ and $\mathrm{G}$ calculated from their values in a mid-point database are identical as percentages, these changes expressed as percentages of the initial values of $\mathrm{C}$ and $\mathrm{G}$ are not identical. It is changes expressed as percentages of initial values that appear in Table 5.1. 
rows 10,11 and 12 , column 1 ) even in the absence of any improvements in $\mathrm{TECH}$ or growth in $\mathrm{L}, \mathrm{K}$ and GDP.

The structural effects in column 1 which produce changes in K, I and GDP can be understood in terms of the GDP identity across the bottom of Figure 5.1. In a situation of little change in I relative to GDP and significant increases in $\mathrm{C}$ and G relative to GDP, the balance of trade (BOT) deteriorates ( 0.21 per cent of GDP, row 1 , column 1$)$. The mechanism is real appreciation (1.47 per cent, row 3 , column 1) which increases imports and reduces exports. For exports we assume that US faces downward-sloping foreign demand curves. Thus, the contraction in exports causes an improvement in the terms of trade ( 0.37 per cent, row 19 , column 1$)$. The terms-of-trade improvement increases the GDP deflator $\left(\mathrm{P}_{\mathrm{g}}\right)$ relative to the price deflator of GNE. This is because the GDP deflator includes the prices of exports but excludes the prices of imports, whereas the opposite is true for the GNE deflator. Even with a terms of trade improvement, it is possible for the price deflator of a component of GNE to increase relative to the price deflator for GDP. However, for a relatively import-intensive component of GNE (e.g. investment) this is unlikely. In column 1 we see that the investment goods price index $\mathrm{P}_{\mathrm{i}}$ falls relative to the price deflator for GDP [compare rows 15 and 17 of column 1]. With the rate of return (the rental price of capital divided by the asset price) held constant, a decrease in $\mathrm{P}_{\mathrm{i}} / \mathrm{P}_{\mathrm{g}}$ generates a decrease in the marginal product of capital (MPK). This follows from the marginal productivity condition for capital:

$$
\text { MPK }=\frac{\text { Rental }}{\mathrm{P}_{\mathrm{g}}}=\frac{\text { Rental }}{\mathrm{P}_{\mathrm{i}}} * \frac{\mathrm{P}_{\mathrm{i}}}{\mathrm{P}_{\mathrm{g}}}=\mathrm{ROR} * \frac{\mathrm{P}_{\mathrm{i}}}{\mathrm{P}_{\mathrm{g}}}
$$

With employment and technology fixed, a decrease in MPK requires an increase in K (row 6, column 1). This produces an increase in both GDP (row 9, column 1) and I (row 7, column 1). The real wage rate rises (row 5, column 1) reflecting the increase in the $\mathrm{K} / \mathrm{L}$ ratio and the consequent increase in the marginal product of labour.

\section{Column 2: shifts in foreign export demands and import prices}

The second column of Table 5.1 shows the additional effects (additional to the momentum effects) of changes over the period 1992 to 1998 in US international trading conditions. We consider import and export markets simultaneously. These markets are interrelated: both are affected by world inflation, the state of the world business cycle and changes in relative prices in major economies.

In the historical simulation we deduced shifts in the export demand curves [fep(i)] from information on changes in export quantities and foreign-currency f.o.b. prices. For imports we assume that the US is a price taker and we treat c.i.f. foreign-currency prices of imports as exogenous in both 
the historical and decomposition closures. ${ }^{17}$ Because our data are for f.o.b. export prices and c.i.f. import prices, column 2 captures the effects of changes both in traded-goods prices on major world markets and of changes in the costs of foreign-provided ${ }^{18}$ transport services used in facilitating flows of commodities into and out of the US.

The decomposition simulation shows that the historically estimated shifts in export demand curves together with the observed changes in import prices were favorable to the US. This is an almost inevitable consequence of growth in the rest-of-world economy. In column 2 of Table 5.1 these changes in international trading conditions improved the terms of trade by 18.79 per cent (row 19). As in the momentum column, the terms-of-trade improvement generates increases in K, GDP, I and the real wage rate (rows 6, 9,7 and 5).

By generating an increase in the price deflator for GDP relative to the price deflator for private and public consumption $\left(\mathrm{P}_{\mathrm{g}} / \mathrm{P}_{\mathrm{c}}\right)$, the terms-of-trade improvement in column 2 causes an increase in "purchasing-power" GNP $\left(=\mathrm{GNP} * \mathrm{P}_{\mathrm{g}} / \mathrm{P}_{\mathrm{c}}\right.$ ) relative to real GDP. This explains the sharp increase in real private and public consumption (which is linked to purchasing-power GNP) relative to real GDP (compare rows 11 and 12 with 9). Via the GDP identity, the sharp increase in real private and public consumption, together with the increase in I, leads to a deterioration in the real balance of trade (export volumes minus import volumes, rows 14 and 13), facilitated by real appreciation (row 3). This deterioration is offset by the terms-of-trade improvement, leaving the change in the nominal balance of trade slightly positive (row 1).

The standard two-good trade model implies that an improvement in the terms of trade leads to a reduction in the output of importables and an increase in the output of exportables. With the balance of trade approximately fixed and with normal preference assumptions, there are increases in the consumption of both importables and exportables. This produces an increase in imports, a relatively small change in exports (either positive or negative) and an overall increase in trade. The results in rows 13 and 14 (a sharp increase in imports and a relatively small decrease in exports) are consistent with these predictions.

\section{Column 3: changes in protection}

Over the period 1992 to 1998, protection fell in most industries. The impact effect on landedduty-paid prices of imported goods was a reduction of about 0.85 per cent. Taking account of the induced devaluation of the exchange rate $(0.45$ per cent, row 4 , Table 5.1$)$, reductions in protection

\footnotetext{
${ }^{17}$ We intend to review this assumption, possibly using long-run GTAP simulations to estimate import supply elasticities to the US.

${ }^{18}$ Recall that in USAGE-ITC, f.o.b. export prices include US-provided transport services outside the US and c.i.f. import prices exclude US-provided transport services outside the US.
} 
lowered landed-duty-paid import prices by about 0.40 per cent. The effect on purchasers' prices was even smaller. Thus, column 3 of Table 5.1 shows only minor macroeconomic effects.

With broad-based reductions in protection, there is stimulation of imports (row 13) and a realdevaluation-induced stimulation of exports (row 14). Expansion of exports causes a reduction in the terms of trade (row 19) leading to a contraction in consumption (rows 11 and 12).

The real wage rate increases by 0.18 per cent (row 5). However, this is the real pre-tax wage rate. If lost tariff revenue is replaced by increased income taxes, the net effect on the real post-tax wage rate is approximately zero ${ }^{19}$. Without replacement of lost tax revenue, the tariff cut causes an initial increase in capital rentals relative to production costs. This allows an increase in the capital/labor ratio (rows 6 and 8). Because $\mathrm{L}$ is fixed $\mathrm{K}$ increases, explaining the increases in GDP (row 9) and investment (row 7).

\section{Column 4: technical change}

The macro effects of the historically estimated movements in technology variables (for example, a0, ac, alprim, a1 and twistlk) are shown in column 4 of Table 5.1. With fixed employment and fixed rates of return on capital, technical improvements increase the real wage rate and increase GDP directly via the production function (line 2, Figure 5.1) and indirectly via increases in the capital stock (lines 5 and 3). In column 4 we find that changes in technology between 1992 and 1998 increased the real wage rate by 8.90 per cent and GDP by 6.67 per cent. The capital stock increased by only 1.11 per cent. For the period 1992 to 1998, our historical simulation revealed strong twists in technology in favor of labor [positive twistlk(j)s]. With technical change having only a minor impact on capital growth, we find in column 4 a reduction in NFL (row 2). The extra investment induced by technical change over the period 1992 to 1998 was outweighed by the extra induced US savings.

Although the increase in GDP in column 4 is only 6.67 per cent, the increases in imports and exports are 15.58 and 38.99 per cent (rows 13 and 14). The sharp increase in exports causes a decline in the terms of trade of 10.87 per cent (row 19). This explains the reductions in private and public consumption relative to GDP (compare rows 11 and 12 with 9). Investment also declines relative to GDP, reflecting subdued growth in capital. The declines in C, G and I relative to GDP explain the movement in the trade balance towards surplus (row 1) and the declines in the real and nominal exchange rates (rows 3 and 4).

There are two reasons that the changes in technology were strongly trade-favoring. First, between 1992 and 1998 it was the export-oriented industries that experienced the largest increases in

\footnotetext{
19 In the decomposition simulation, we avoid modelling the revenue replacement tax by assuming (a) that revenue replacement is via a non-distorting tax (e.g. a tax on labour income with fixed labour supply) and (b)
} 
total factor productivity. We found that the weighted average in the entries in column 5 of Table 4.2 was 4 per cent when we used export weights but only 2 per cent when we used value added weights. Second, the movements in technology happened to favor the use of inputs that are heavily imported, particularly computers. With import weights, the weighted average of the entries in column 2 of Table 4.2 is 8.5 and with value added weights it is only 0.9 .

\section{Column 5: changes in import/domestic preferences}

Column 5 shows the macro effects of import/domestic twists [the ftwist(i)s] over the period 1992 to 1998.

In aggregate, the twists were slightly in favor of imports. The effect of the ftwist(i)s on import volumes in column 5 of Table 5.1 is an increase of 2.8 per cent. With L, ROR and TECH held constant, Figure 5.1 suggests that the ftwist(i)s should have little effect on $\mathrm{K}$ and I. This is borne out in rows 6 and 7. With little impact on I there is little impact on the balance of trade (row 1). Thus the ftwist(i)s are accompanied by an increase in exports to match the increase in imports, requiring real devaluation (2.55 per cent, row 3$)$. The percentage increase in export volumes exceeds that in import volumes because export expansion causes a decline in the terms of trade. The terms-of-trade decline reduces purchasing-power GNP and real private and public consumption.

Another effect of the reduction in the terms of trade is to increase $P_{i} / P_{g}$ (rows 17 and 15). Via (5.1), this increases MPK, reducing MPL and the real wage rate (row 5). With an increase in MPK, there are decreases in $\mathrm{K}$ and $\mathrm{I}$.

Column 6: the effects of changes in consumer preferences, i.e., changes in the parameters of the household utility function

Column 6 in Table 5.1 shows the effects of the estimated changes in preferences [a3com(i) ave_a3com] between 1992 and 1998. The macroeconomic effects of these changes are small. Because production of cigarettes, alcohol and other commodities which suffered adverse preference shifts is capital intensive relative to production of boats, travel trailers and other commodities which enjoyed favorable preference shifts, we find small reductions in column 6 in capital, investment and GDP (rows 6, 7 and 9). Another feature of cigarettes and alcohol is that they are heavily taxed whereas boats etc. are relatively lightly taxed. A shift in consumption against heavily taxed commodities towards lightly taxed commodities tends to reduce GDP. This explains the relatively large negative entry for real GDP in row $9 .^{20}$ Another effect of the heavy taxation of cigarettes and alcohol can be seen in the result for the real wage rate. In the decomposition simulation we have not

that consumption is determined in each column of the decomposition table independently of disposable income as an exogenously given share of GNP. 
allowed for replacement of tax revenue lost by the shift in preferences away from cigarettes etc. This explains the increase in the real wage rate shown in column 6 (row 5). A final interesting feature of the preference changes over the period 1992 to 1998 is that they favored commodities that happened to be heavily imported. The weighted average of the a3com(i)s using commodity shares in household consumption of domestic goods is slightly negative whereas the weighted average using commodity shares in household consumption of imported goods is significantly positive. This explains the increase in imports in row 13 of column 6 . With C, I and G all falling by about the same percentage as GDP, and with imports increasing, exports must increase (row 14). The increase in exports generates a reduction in the terms of trade.

Column 7: the effects of employment growth and growth in the number of households

Column 7 of Table 5.1 shows the effects over the period 1992 to 1998 of growth in employment (13.7 per cent) and in other population-related variables (e.g. the number of households).

With constant returns to scale, fixed rates of return, fixed $\mathrm{I} / \mathrm{K}$ ratios and no change in technology, we would expect the system depicted by lines (1) - (7) and (16) - (17) in Figure 5.1 to transform a 13.7 per cent increase in employment into 13.7 per cent increases in K, I and GDP with no change in the real wage rate. However, a larger domestic economy produces more exports with an associated decline in the terms of trade. This increases $\mathrm{P}_{\mathrm{i}} / \mathrm{P}_{\mathrm{g}}$ (rows 17 and 15), restricting the increases in K and GDP to 12.59 and 13.53 per cent [see (5.1)]. With a reduction in the $\mathrm{K} / \mathrm{L}$ ratio, there is a reduction in the marginal product of labour and in the real wage rate (row 5).

By causing an increase in $\mathrm{P}_{\mathrm{c}} / \mathrm{P}_{\mathrm{g}}$, terms-of-trade deterioration in column 7 is a factor in limiting the growth in real private and public consumption to 12.27 and 11.35 per cent, well below that of real GDP, 13.53 per cent. Another factor is accumulation of foreign liabilities, reflecting rapid growth in $\mathrm{K}$. The increase in NFL restricts consumption by restricting the growth in real GNP (12.82 per cent, row 10$)$.

With subdued growth in private and public consumption relative to GDP, column 7 shows a 11.4 percentage point gap between export and import growth. This is facilitated by real devaluation of 7.77 per cent (row 3). Real devaluation increases the export share in GDP and reduces the import share.

Column 8: the effects of apparent changes in profitability [the powtaxOph(j)s]

On average the profitability of US industries increased between 1992 and 1998 by about 1.25 per cent of sales. In terms of Figure 5.1, we can think of column 8 as being generated by the imposition of a positive shock to ROR, holding constant L and TECH. Consistent with this

${ }^{20}$ On the basis of the reduction in capital ( 0.67 per cent, row 6$)$ we would have expected a reduction in real 
representation, column 8 shows decreases in K, I, GDP and the real wage rate. NFL declines in response to the decrease in K. This allows GNP to increase slightly relative to GDP. Nevertheless, private and public consumption declines relative to GDP. This is caused mainly by terms-of-trade decline (row 19) associated with an increase in exports (row 14). Exports increase because the decline in absorption, particularly investment, relative to GDP is sufficient to ensure an increase in the trade balance. This is facilitated by export-enhancing real devaluation (row 3). The decline in GDP and the real devaluation cause imports to fall (row 13).

One surprising aspect of the results in column 8 is the extent of the decline in GDP, 1.98 per cent (row 9). With returns to capital accounting for 30 per cent of primary-factor income we would expect the GDP decline in column 8 to be about 30 per cent of the decline in capital, i.e. about 1 per cent $(=0.3 * 3.35)$. The additional decline in GDP is caused by dead-weight losses associated with the imposition of phantom production taxes. Some of these production taxes are large positives (e.g. rates of between 20 and 30 per cent for Funeral services, Banking and Cement) and some are large negatives (e.g. rates of about -50 per cent for computer products). To the extent that our phantom production taxes reflect pure profits and losses, the additional GDP loss in column 8 (beyond that associated with the reduction in capital) is a legitimate reflection of mis-pricing of goods and services. However, we suspect that the large phantom taxes (both positive and negative) mainly reflect contradictions in the statistics on prices and costs. With more compatible statistics, we would expect some of the GDP change in column 8 to be transferred to other columns.

Given dead-weight tax losses of about 1 per cent of GDP, we might expect a decline in GNP of about 1 per cent. However, the decline in GNP is 1.84 per cent (row 10). The extra 0.84 per cent reduction in GNP is explained by two factors. First, the rate of interest on US foreign debt during the period 1992 to 1998 was extremely low, about 2 per cent. This means that the loss of capital in column 8 reduces GDP without an equivalent reduction in interest payments to foreigners. Thus the loss of capital in column 8 causes a reduction in GNP. Second, the reduction in the terms of trade and the deadweight tax losses are assumed to occur smoothly over the six year period from 1992 to 1998. This reduces savings in each of the years 1993 to 1997 thereby reducing US ownership of capital in 1998. This has a negative impact on GNP in 1998.

\section{Column 9: the effects of shifts in export supply curves}

In the historical simulation, we accommodated observed changes in export prices and volumes by endogenizing the positions of the export demand curves and the levels of supply-shifting export taxes and subsidies (phantoms). In the decomposition simulation the demand and supply shift variables are exogenous. The effects of the demand shift variables have already been discussed in

GDP of about 0.22 per cent. Instead the reduction is 0.49 per cent. 
relation to column 2 of Table 5.1. The effects of the supply-shift variables (phantom export taxes and subsidies) are given in column 9.

The average rate of phantom export tax was -3.3 per cent implying that US export supply curves moved down. This produced an increase in exports (row 14), a decline in the terms of trade (row 19) and real appreciation (row 3). The real appreciation caused an increase in imports (row 13) and the decline in the terms of trade caused cuts in private and public consumption (rows 11 and 12). The increase in capital and investment (rows 6 and 7) reflects the capital intensity of US export industries relative to import competing industries.

\section{Column 10: Other factors}

Decomposition simulations allow us to look at the effects of an overwhelming number of exogenous variables. Inevitably, we must terminate the process by having an "other column". Here, this is column 10 of Table 5.1.

The main shocks in column 10 are to macro ratios. Recall from lines (7) and (10) in Figure 5.1 that in the decomposition simulation we exogenize $\mathrm{I} / \mathrm{K}$ ratios and the average propensities to consume (C/GNP, G/GNP). In columns 1 to 9 of Table 5.1, these ratios were fixed. In column 10 we introduce, as exogenous shocks, the changes in these ratios that were endogenously determined in the historical simulation. Also included in column 10 are the effects of shocks to relative sectoral wage rates and to the overall price level.

For most sectors, the $\mathrm{I} / \mathrm{K}$ ratio was higher in 1998 than in 1992, explaining the strongly positive result in column 10 for real investment (row 7). The C/GNP ratio was higher in 1998 than in 1992, explaining the positive result for real private consumption (row 11). On the other hand, the G/GNP ratio fell between 1992 and 1998, explaining the negative result for public consumption (row 12). Overall there was a slight fall in total consumption (private and public) relative to GNP. This was easily outweighed by the increase in investment relative to GNP. Thus in column 10 we find a strong movement to balance of trade deficit (row 1), facilitated by real appreciation (row 3). Real appreciation explains sharp contraction in exports (row 14), improvement in the terms of trade (row 19) and expansion in imports (row 13).

Column 10 shows a reduction in net foreign liabilities as a per cent of GDP (row 2). As well as changes in macro ratios, column 10 includes the effects of the overall increases in the US price level (a 12.16 per cent increase in the consumption deflator, row 16). Because a considerable fraction of US foreign liabilities is repayable in US dollars, general domestic inflation has the effect of reducing US foreign liabilities relative to GDP. 


\subsection{Cross-column analysis: growth in US trade between 1992 and 1998}

Why did US trade grow so fast between 1992 and $1998 ?$

The first three rows of Table 5.1A are taken from Table 5.1. The fourth row shows percentage increases in the volume of US trade calculated as the average of the percentage increases in imports and exports. The final row in Table 5.1A gives percentage increases in trade relative to GDP calculated by subtracting the percentage increase in GDP (row 1) from the percentage increase in trade (row 4).

The final entry in the fifth row of Table 5.1A shows that trade as a share of GDP increased by 37.16 per cent? Well over half of this ( 20.62 percentage points) was contributed by technology. As explained in our discussion of column 4, technological change between 1992 and 1998 was strongly trade favoring because total-factor-productivity growth was relatively rapid in export-oriented industries and because movements in technology happened to favor the use of inputs that are heavily imported, particularly computers.

The second largest entry in row 5 of Table 5.1A is for changes in trading conditions $(6.38$ percentage points, column 2, Table 5.1A). To a large extent, this entry gives the effects on US trade of growth in the rest of the world. With growth in the world economy, the US benefited from outward shifts in foreign demand curves for its exports and from outward shifts in foreign supply curves for its imports. As reflected in column 2 of Table 5.1, these demand and supply shifts generated a sharp improvement in the US terms of trade. This was trade expanding because it allowed strong import growth with only a small contraction in exports.

Twists in industry and household preferences towards imports (column 5, Table 5.1A) and changes in household preferences between commodities (column 6, Table 5.1A) each contributed about 4 percentage points to growth in US trade relative to GDP. Preference twists towards imports directly increased imports and indirectly increased exports via real devaluation (see discussion of column 5). Changes in household preferences stimulated trade by increasing demand for some commodities that heavily imported [e.g. computer products (commodities 316 to 319, see last column of Table 4.2), boats (360), luggage (209) and holidays (497)] while decreasing demand for some other commodities that are lightly imported [e.g. cigarettes (98) and malt beverages (82)].

Column 8 of row 5 in Table 5.1A shows a positive contribution of 2.65 percentage points to growth in trade relative to GDP. On the other hand, the entry in row 10 shows a negative contribution of 4.94 percentage points. The main macro feature of column 8 in Table 5.1 is a decrease in investment (associated with a positive shock to ROR) while the main macro feature of column 10 is an increase in investment (associated with an increase in I/K ratios). In USAGE-ITC, it is apparent that autonomous increases in investment are trade-contracting. 
Whether autonomous increases in investment are trade-contracting or expanding depends on whether the necessary transfer of resources into construction and other investment related activities is mainly at the expense of export or import-competing production. If the bulk of the transfer were out of import-competing production, then trade would expand. However, in USAGE-ITC, the bulk of the transfer is out of the production of goods for export. This implies that increases in investment are trade-contracting. The Armington elasticities in USAGE-ITC average about 2. With these values, there is limited scope for reducing production of import-competing goods as a share of absorption $(\mathrm{C}+\mathrm{I}+\mathrm{G})$.

As could be anticipated from our discussion of column 9 in Table 5.1, column 9 in Table 5.1A contains a positive entry in row 5. Outward movements in US export-supply curves were tradeexpanding. However, the contribution of these movements to growth in the trade to GDP ratio was minor, 2.64 percentage points.

The remaining entries (those in columns 1, 3 and 7) in row 5 of Table 5.1A are small, having absolute values of less than one percentage point. It is interesting to note that these entries include the effects of reductions in tariffs. Tariff reductions are often cited as a major cause of trade growth. However, for the US between 1992 and 1998 their contribution to growth in the trade to GDP ratio was only 0.87 percentage points. As mentioned in our discussion of column 3 in Table 5.1, cuts in tariffs between 1992 and 1998 reduced landed-duty-paid import prices by less than one per cent.

\subsection{Decomposition simulation: results for Iron \& Steel (IS) and Iron \& Steel Forging (ISF)}

In this subsection we illustrate the application of USAGE-ITC decomposition simulations to the analysis of particular industries. The example we choose is iron and steel.

Table 5.2 contains decomposition results relevant to understanding growth between 1992 and 1998 in US output of Iron \& Steel and Iron \& Steel Forging (commodities 240 and 241). The first row in Table 5.2 contains the GDP results from Table 5.1. The results in all the subsequent rows are expressed relative to the GDP results. For example, rows 2 and 3 show percentage changes in output of Iron \& Steel and Iron \& Steel Forging less the percentage change in the relevant column of real GDP. Thus, in the first column the percentage change in the output of Iron \& Steel is -1.93 $(=-2.41+0.48)$.

The entries in the total column of rows 2 and 3 show, for the period 1992 to 1998, that output of Iron \& Steel increased by 6.81 per cent relative to GDP and output of Iron \& Steel Forging increased by 20.59 per cent relative to GDP. The dominant contributor to relative output growth for both commodities was technical change (column 4). The only other non-negligible contributing factor was employment growth (column 7).

Why was technical change the dominant contributor to relative output growth for both these commodities? As can be seen from column 5 of Table 4.2 (rows 240 and 241), production of both 
commodities benefited from above average all-input-saving technical change (6.81 per cent and 8.29 per cent compared with an average over all commodities of about 2 per cent). However, neither commodity had significant direct exposure to international trade in the period 1992 to 1998 . Their export shares were 2.94 and 0.03 per cent and their import shares were 1.80 and 0.00 per cent (columns 11 and 14 in Table 4.2). USAGE-ITC implies low price elasticities of demand for commodities with export and import shares close to zero. Thus, in our decomposition simulation, cost-reducing technical change in the production of these commodities does not, by itself, strongly enhance output. Nor can we find the answer to the above-average performances of Iron \& Steel and Iron \& Steel Forging in column 4 of Table 5.2 in technical change that uses the two commodities. The entry for commodity 240 in column 2 of Table 4.2 is negative while that for commodity 241 is only a small positive. Thus output growth for commodity 240 was reduced by Iron $\&$ Steel-saving technical change, and output growth for commodity 241 was only slightly increased by technical change favoring the use of Iron \& Steel Forging. To find the answer to our question we must look at the effects of technical change on the users of Iron \& Steel and Iron \& Steel Forging.

Rows 4 and 5 of Table 5.2 show growth in output relative to GDP in the industries that use Iron $\&$ Steel and in the industries that use Iron \& Steel Forging. The two rows were calculated as weighted averages across all industries of output changes relative to GDP: in row 4, the weights are industry shares in domestic sales of US Iron \& Steel and in row 5 they are industry shares in domestic sales of US Iron \& Steel Forging. ${ }^{21}$ Now we see that relative growth in the output of commodities 240 and 241 can be explained by relative growth in the outputs of the industries that use these commodities. With one exception, the entries in row 4 for Iron \& Steel users are close to the entries in row 2 for relative Iron \& Steel output, and with no exceptions, the entries in row 5 for users of Iron \& Steel Forging are close to the entries in row 3 for relative Iron \& Steel Forging output. The exception for Iron \& Steel is in column 4. Whereas relative output growth for Iron \& Steel in column 4 is 6.70 per cent, relative output growth for Iron \& Steel users is 16.02 per cent. In column 4, Iron \& Steelsaving technical change (see Table 4.2, row 240, column 2) causes Iron \& Steel output to expand at a considerably slower rate than the output of Iron and Steel users.

At this stage, to understand the strong performance of Iron \& Steel and Iron \& Steel Forging in column 4 of Table 5.2, we need to understand the strong performance of their user industries. For both commodities, the most important using industry is Motor Vehicle Parts, accounting for 17 per cent of the sales of Iron \& Steel and 18.5 per cent of the sales of Iron and Steel Forging. The second most important using industry is Internal Combustion Engines, accounting for 8.2 per cent of the sales of Iron \& Steel and 13.4 per cent of the sales of Iron and Steel Forging. The other major users of the

\footnotetext{
21 All of US domestic sales of both Iron \& Steel and Iron \& Steel Forging are to industries as inputs to current production.
} 
two commodities are various investment-related industries such as Pipes, Construction Machinery and Non Residential Construction. Rows 6 and 7 of Table 5.2 show decomposition results for output relative to GDP for the two major using industries (Motor Vehicle Parts and Internal Combustion Engines) and row 8 shows results for aggregate real investment relative to GDP.

The two major using industries perform strongly in column 4 of Table 5.2 because both are trade exposed (having high export and import shares, see the entries in columns 11 and 14 of rows 281 and 355 in Table 4.2) and both benefit in column 4 from reductions in their costs per unit of output. These reductions reflect higher than average rates of technical change in the production of the two commodities (3.56 per cent and 8.39 per cent, rows 355 and 281 of column 5 in Table 4.2) and higher than average rates of technical change in the production of inputs to the two commodities, including inputs of Iron \& Steel and Iron \& Steel Forging. For Motor Vehicle Parts, the reduction in costs per unit of output is 4.49 per cent and for Internal Combustion engines it is 13.4 per cent. Together with devaluation of 4.92 per cent (row 3, column 4, Table 5.1), these reduction in costs per unit of output translate into cuts in foreign-currency prices of about 9 and 18 per cent, strongly stimulating exports of both Motor Vehicle Parts and Internal Combustion Engines. At the same time, the 9 and 18 per cent cuts in foreign-currency prices of the two US products allow them to replace considerable amounts of imports.

In summary our analysis suggests that output growth in Iron \& Steel and Iron \& Steel Forging between 1992 and 1998 exceeded growth in GDP mainly because technical change during this period strongly stimulated output growth in the major customers for these products. Both the major customers, Motor Vehicle Parts and Internal Combustion Engines, have high export and import shares. Their own technical change and that of their suppliers (including Iron \& Steel and Iron \& Steel Forging) sharply improved the international competitiveness of the US Motor Vehicle Parts and Internal Combustion Engine industries. Export expansion and import replacement by these industries then generated strong growth in the outputs of Iron \& Steel and Iron \& Steel Forging.

\section{Concluding remarks}

This paper reports our first historical and decomposition simulations using USAGE-ITC. Refined versions of these simulations will be important in subsequent work on the USAGE-ITC project.

In 2001 when we started work on this paper, the most recently published comprehensive input-output table for the US was the BEA's 500-order benchmark data for 1992. By generating prices and quantities for all input-output flows for 1998, our historical simulation provides an update of the BEA's benchmark data to 1998. The update incorporates detailed data on: industry and commodity outputs; prices and quantities for exports and imports; quantities for private and public consumption; and quantities for capital, investment and employment by industry. By using an 
historical simulation for updating we can not only incorporate all the available detailed data, but we can also use data on one variable to fill gaps in our knowledge of other variables. For example, in the historical simulation for 1992 to 1998, we had observations for movements in consumption from the 192-order BLS input-output tables. For imports, our observations were at the more detailed 500-order level. These import observations not only informed our estimates of flows of imports to industries and final users in the updated input-output table, but also our estimates of consumption at the 500-level. If imports of 500-order commodity i grew rapidly relative to imports of other commodities in the same BLS category, then our historical simulation captures the idea that consumption of commodity $i$ is likely to have grown rapidly relative to consumption of other commodities in the relevant BLS category.

Updated input-output data are important for policy analysis and essential in forecasting. Policy analysis based on outdated data is too easily dismissed by critics and may sometimes genuinely miss important aspects of the issue under investigation. For example, an analysis of the stevedoring industry based on 1992 data would underestimate the benefits of cost-reducing reforms by understating the current importance in the US economy of international trade. In forecasting, up-todate input-output data are an unavoidable requirement if we want to say anything about likely developments in investment-related industries. From projections of demographic and income variables, we may be reasonably confident that the nation's housing stock will grow by about 2 per cent a year over the next five years. However, unless we have a database which reflects the current year's construction activity, we have little basis for deciding whether 2 per cent housing growth implies strong or weak growth in the construction sector and related industries such as timber, bricks and cement.

A co-product of the updated input-output data produced by an historical simulation is detailed estimates of changes in technologies (changes in production functions) and changes in consumer preferences (changes in the utility function). For the period 1992 to 1998 we estimated several aspects of technology change for about 500 industries including: changes in multi-factor productivity (total inputs per unit of output); changes in input-using technology affecting the use of each industry's products per unit of output throughout all industries; changes in capital/labor choices beyond those that can be explained by changes in relative factor prices; and changes in choices between imported and domestic inputs beyond those that can be explained by changes in relative import/domestic prices. We also estimated changes in consumer preferences for about 500 commodities. In the further development of the USAGE-ITC project, extrapolations of changes in technologies and consumer preferences estimated in an historical simulation will be important for giving forecast simulations convincing industrial detail. 
Having completed an historical simulation for 1992 to 1998 , we were immediately able to conduct a decomposition simulation. Such simulations can be used to explain movements in an enormous variety of macro and micro variables. In this paper we illustrated the application of the decomposition technique in a discussion for 1992 to 1998 of growth in US trade (macro) and growth in US output of Iron \& Steel and Iron \& Steel Forging (micro). Decomposition simulations can play an important role in policy analysis by providing quantitative evidence on the effects of policy changes in the past relative to the effects of changes in other exogenous variables representing, for example, technologies, consumer preferences and world commodity prices.

Analysis of our results from the historical and decomposition simulations revealed several areas for further work. In the next version of our historical and decomposition simulations for 1992 to 1998, we would like to recognize: that the US does not face infinitely elastic supply curves for its imports; that aggregate private consumption is more closely linked to household disposable income than to GNP; that expenditure elasticities of demand are not all unity, with those for food products being less than one and those for luxury products such as boats being more than one; and that our current specification of pro-cyclical twists in import/domestic preferences is probably too extreme, causing an overstatement of the autonomous twists (ftwist) towards imports for commodities in which US output is declining (e.g. footwear) and an overstatement of the autonomous twists against imports for commodities in which US output is expanding rapidly (e.g. computers). None of these areas is particularly difficult and satisfactory resolutions will be possible with a few weeks effort.

The major decision now to be made for historical and decomposition analysis with USAGEITC concerns the period 1998 to 2003. As we have already explained, up-to-date input-output data are essential for forecasting. Thus we will need to move on from 1998. The BEA has now published benchmark 500-order input-output data for 1997. Unfortunately these data are on a different industrial classification (NAICS rather than SIC) from that used in the 1992 table and in USAGE-ITC. This feature of the 1997 data, together with the recentness of its publication, has limited its usefulness in the work reported in this paper. However, eventually it is likely that the 1997 data will become the starting point for historical and decomposition analysis designed to cover the period 1997 to the present time.

Re-basing USAGE-ITC to 1997 and conducting historical and decomposition simulations for 1997 to 2003 will be a large task. For our work on 1992 to 1998 it was necessary to make major reorganizations in the treatments of indirect taxes and value added in the BEA data for 1992. We also spent many months processing data for 1992 to 1998. A full historical and decomposition analysis covering 1997 to 2003 would require similar extensive reorganization of the BEA 1997 input-output data and considerable effort in processing data for 1997 to 2003. A more practical approach over the next few months, an approach designed to achieve forecast and policy results within the next year, will be to conduct a partial update for the period 1998 to 2003 starting from the 1998 database generated in 
our current historical simulation. The partial update will be achieved by an historical simulation that takes into account movements in all macro variables between 1998 and 2003. Most micro data for this period is available on NAICS rather than on SIC. However, it will be possible in an historical simulation for 1998 to 2003 to introduce these micro data at relatively aggregated levels, levels at which differences between NAICS and SIC are unimportant. 


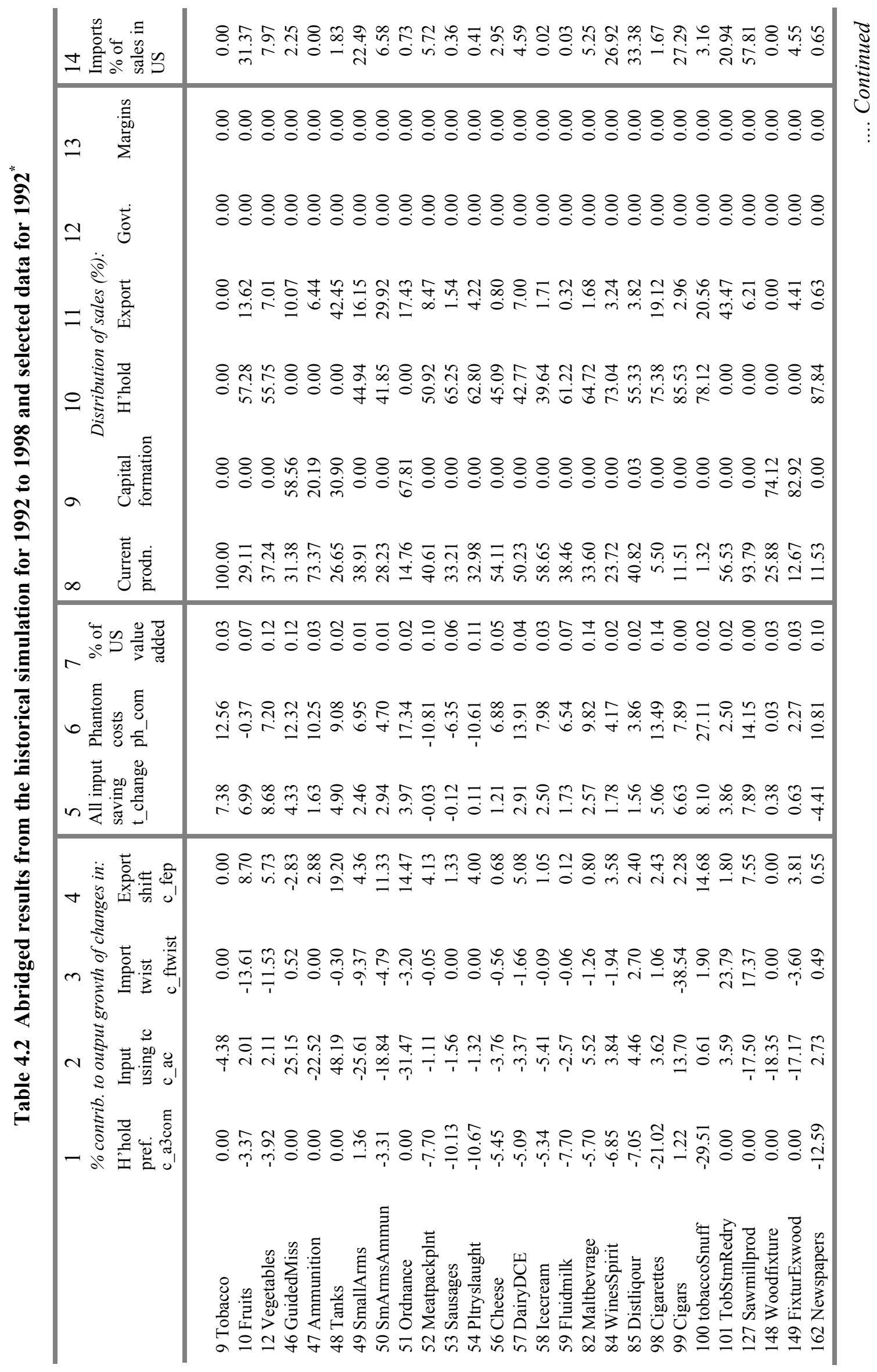




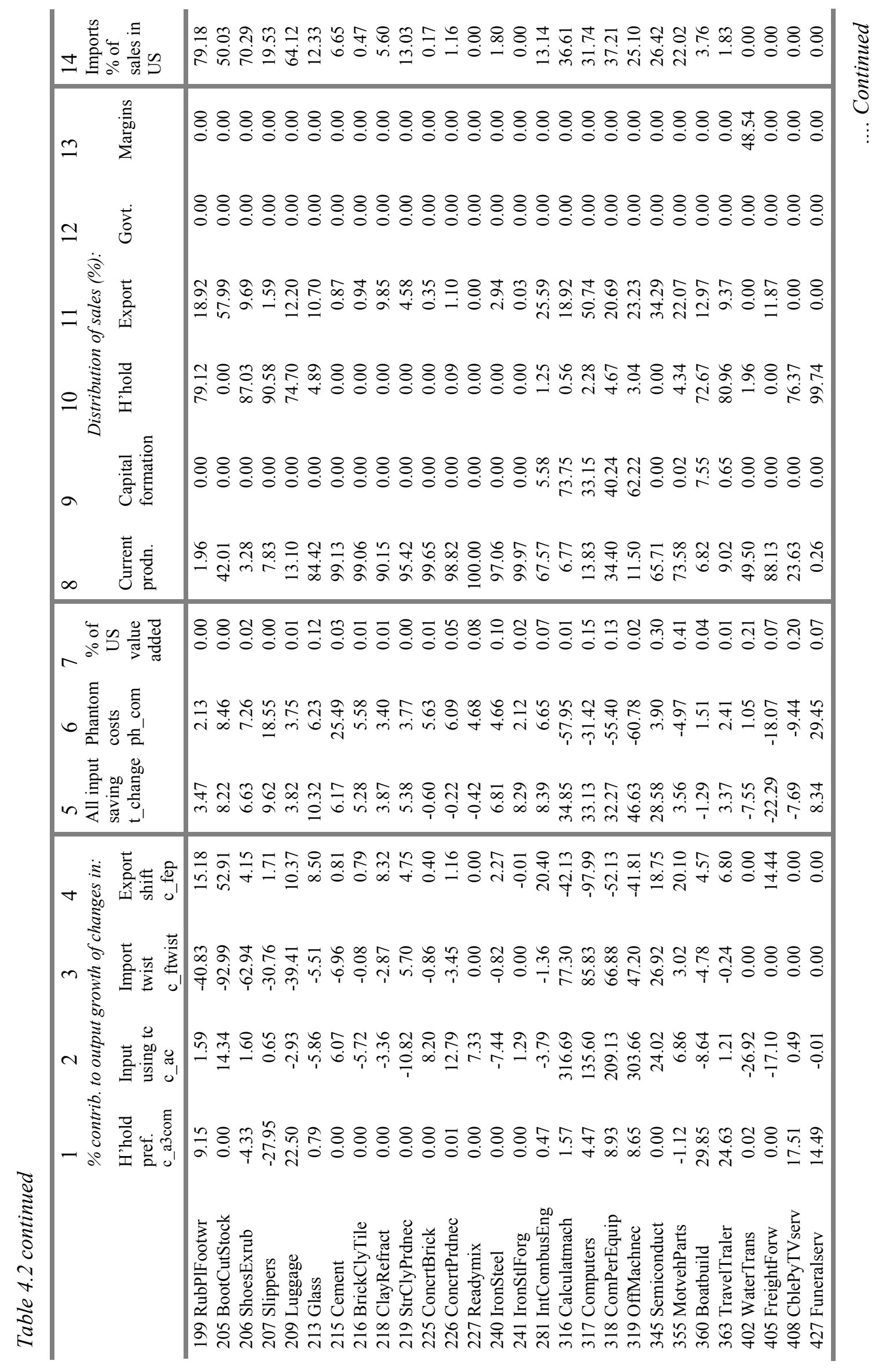




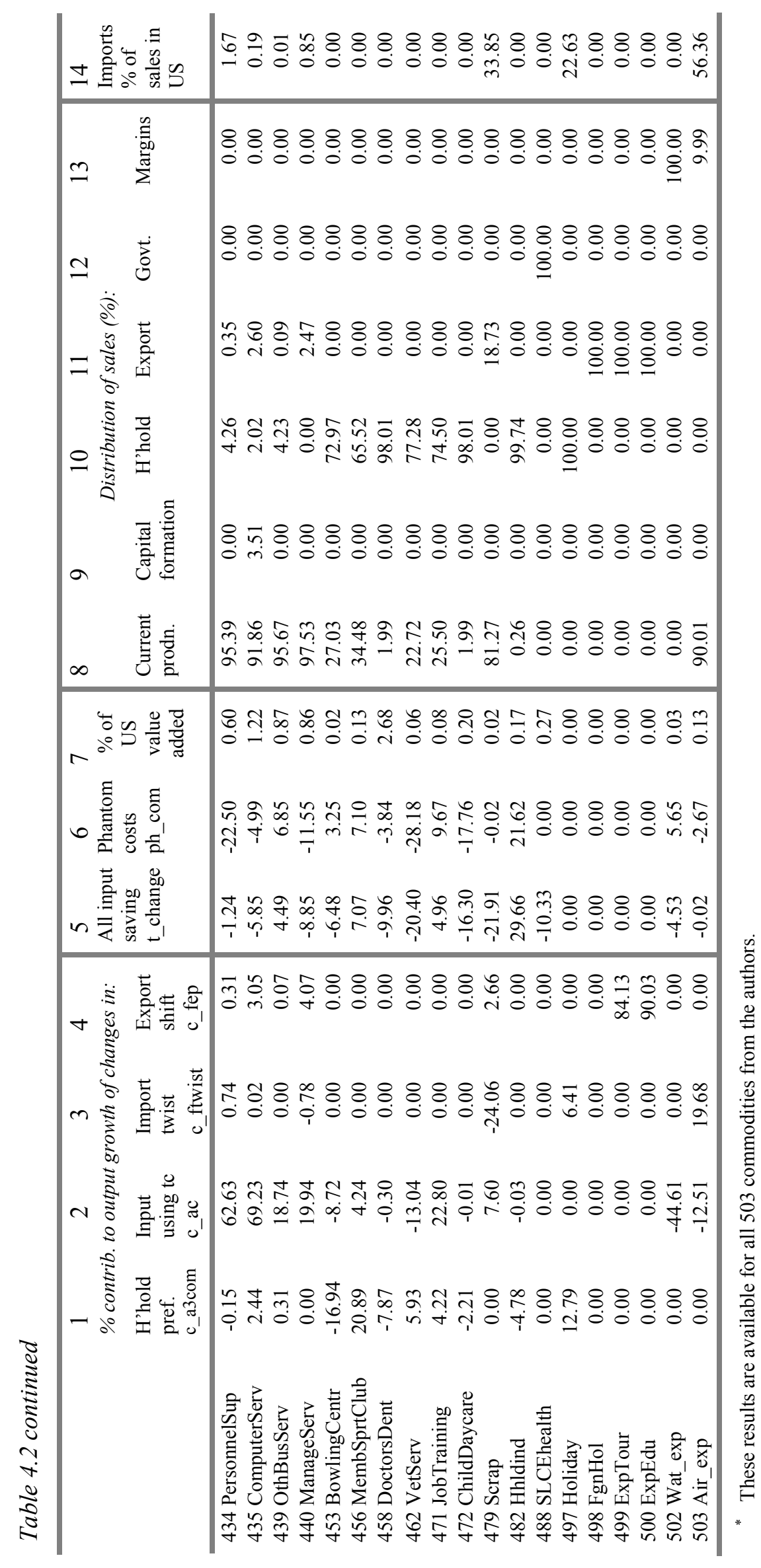




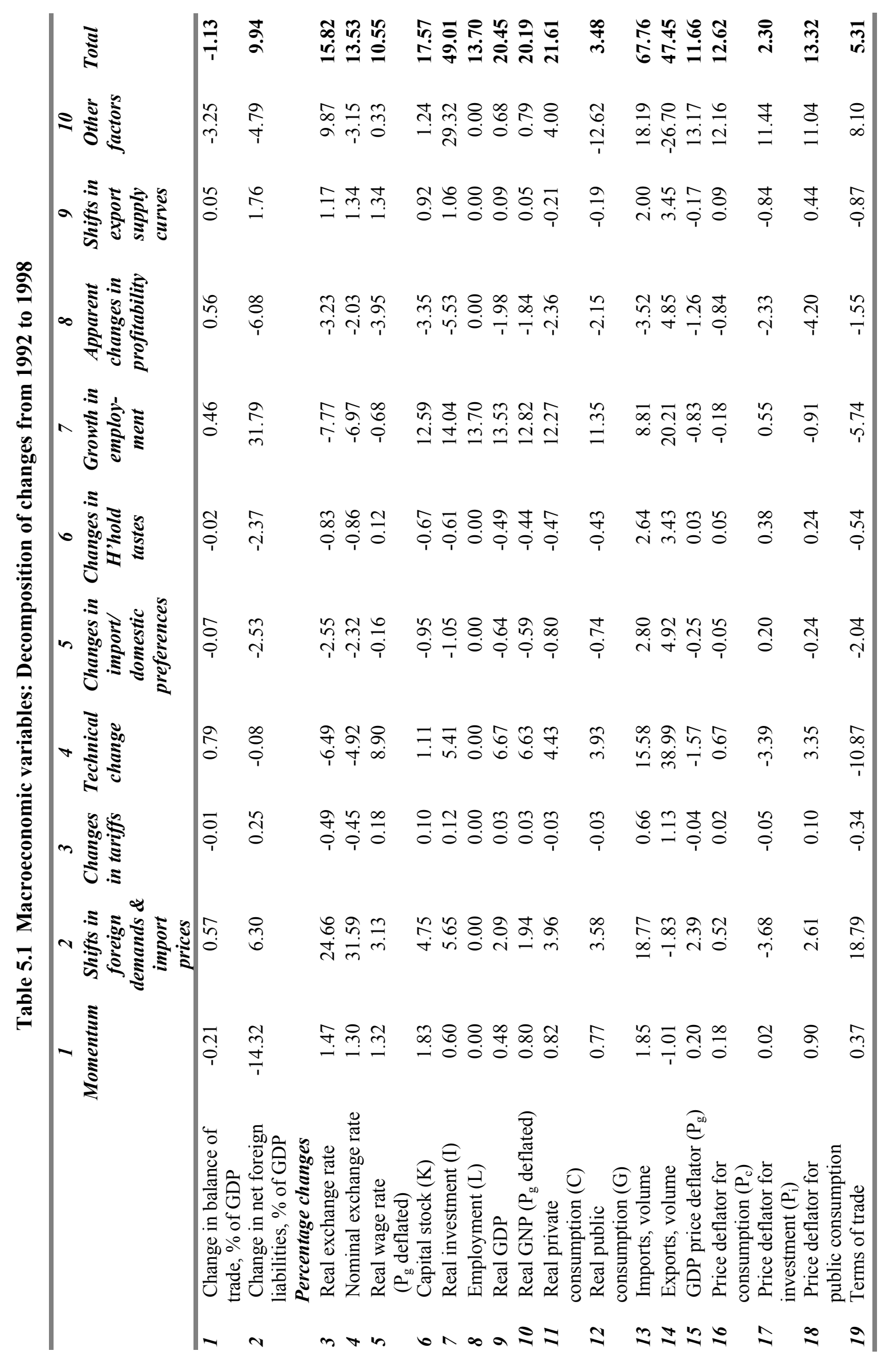



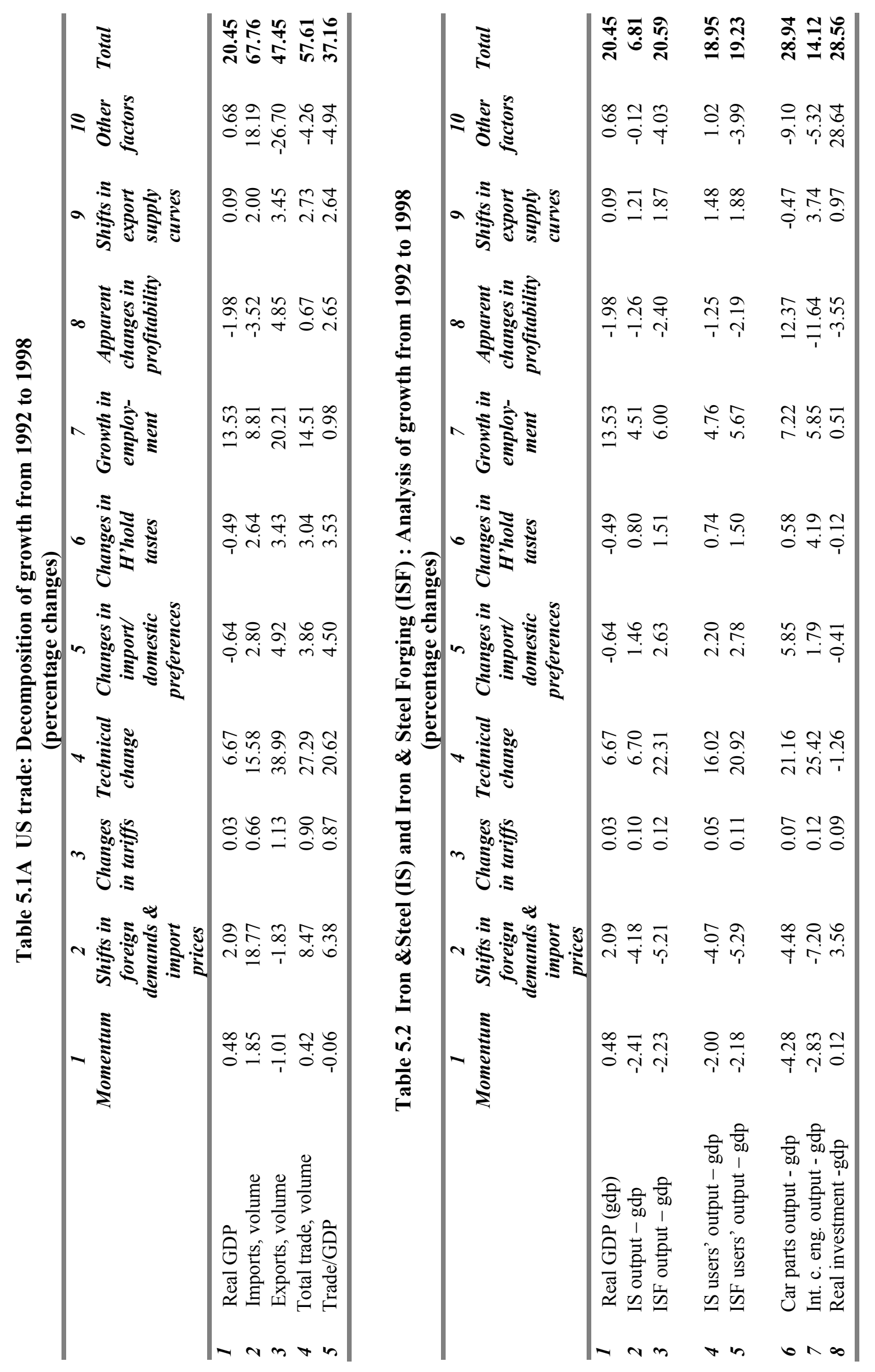


\section{References}

Armington, Paul S. (1969) "The Geographic Pattern of Trade and the Effects of Price Changes", IMF Staff Papers, XVI, July, pp. 176-199.

Armington, Paul S. (1970) "Adjustment of Trade Balances: Some Experiments with a Model of Trade Among Many Countries", IMF Staff Papers, XVII, November, pp. 488-523.

Dixon, P.B. and M.T. Rimmer, Dynamic General Equilibrium Modelling for Forecasting and Policy: a Practical Guide and Documentation of MONASH, Contributions to Economic Analysis 256, NorthHolland Publishing Company, 2002, pp.xiv +338 .

Dixon, P.B., S. Bowles and D. Kendrick (1980), Notes and Problems in Microeconomic Theory, North-Holland Publishing Company, Amsterdam.

Dixon, P.B., B.R. Parmenter, J. Sutton and D.P. Vincent (1982), ORANI: A Multisectoral Model of the Australian Economy, North-Holland, Amsterdam.

Harrison, W.J. and K.R. Pearson (1996), "Computing Solutions for Large General Equilibrium Models Using GEMPACK”, Computational Economics, Vol. 9, pp. 83-127.

Harrison, W.J., J.M. Horridge and K.R. Pearson (2000), "Decomposing simulation results with respect to exogenous shocks", Computational Economics, 15, pp. 227-249.

Harrison, W.J., K.R. Pearson and A.A. Powell (1996), "Features of Multiregional and Intertemporal AGE Modelling with GEMPACK”, Computational Economics, Vol. 9, pp. 331-353.

Hertel, T.W., editor (1997), Global Trade Analysis: Modeling and Applications, Cambridge University Press, Cambridge, U.K.

Pearson, K.R. (1988), "Automating the Computation of Solutions of Large Economic Models", Economic Modelling, Vol. 7, pp. 385-395. 